\title{
Kv2 Channel Regulation of Action Potential Repolarization and Firing Patterns in Superior Cervical Ganglion Neurons and Hippocampal CA1 Pyramidal Neurons
}

\author{
Pin W. Liu and Bruce P. Bean \\ Department of Neurobiology, Harvard Medical School, Boston, Massachusetts 02115
}

\begin{abstract}
Kv2 family "delayed-rectifier" potassium channels are widely expressed in mammalian neurons. Kv2 channels activate relatively slowly and their contribution to action potential repolarization under physiological conditions has been unclear. We explored the function of Kv2 channels using a Kv2-selective blocker, Guangxitoxin-1E (GxTX-1E). Using acutely isolated neurons, mixed voltage-clamp and current-clamp experiments were done at $37^{\circ} \mathrm{C}$ to study the physiological kinetics of channel gating and action potentials. In both rat superior cervical ganglion (SCG) neurons and mouse hippocampal CA1 pyramidal neurons, $100 \mathrm{~nm}$ GxTX-1E produced near-saturating block of a component of current typically constituting $\sim 60-80 \%$ of the total delayed-rectifier current. GxTX-1E also reduced A-type potassium current $\left(I_{\mathrm{A}}\right)$, but much more weakly. In SCG neurons, $100 \mathrm{nM}$ GxTX-1E broadened spikes and voltage clamp experiments using action potential waveforms showed that Kv2 channels carry $\sim 55 \%$ of the total outward current during action potential repolarization despite activating relatively late in the spike. In CA1 neurons, $100 \mathrm{~nm} \mathrm{GxTX-1E} \mathrm{broadened} \mathrm{spikes} \mathrm{evoked} \mathrm{from}-70 \mathrm{mV}$, but not $-80 \mathrm{mV}$, likely reflecting a greater role of Kv 2 when other potassium channels were partially inactivated at $-70 \mathrm{mV}$. In both CA1 and SCG neurons, inhibition of Kv2 channels produced dramatic depolarization of interspike voltages during repetitive firing. In CA1 neurons and some SCG neurons, this was associated with increased initial firing frequency. In all neurons, inhibition of Kv2 channels depressed maintained firing because neurons entered depolarization block more readily. Therefore, Kv2 channels can either decrease or increase neuronal excitability depending on the time scale of excitation.
\end{abstract}

Key words: activation; deactivation; delayed-rectifier potassium channel; Guangxitoxin; Hodgkin-Huxley kinetics; Kv2

\section{Introduction}

Mammalian neurons express multiple types of voltage-gated potassium channels that activate with different voltage dependence and kinetics and together enable a wide range of firing patterns (Hille, 2001; Trimmer and Rhodes, 2004; Vacher et al., 2008; Johnston et al., 2010). Among the most widely expressed potassium channels in neurons of the mammalian brain are Kv2 family channels (Trimmer, 1991; Hwang et al., 1993; Scannevin et al., 1996; Du et al., 1998, 2000; Guan et al., 2007). Kv2 channels produce "delayed-rectifier" currents that activate more slowly than many other voltage-dependent potassium channels, including most Kv1, Kv3, and Kv4 family channels. Knock-down of Kv2 with antisense or dominant-negative expression has suggested that Kv2 channels are activated only minimally during single action potentials in cortical or CA1 pyramidal neurons (Du et al.,

\footnotetext{
Received May 7, 2013; revised Feb. 24, 2014; accepted Feb. 27, 2014.

Author contributions: P.W.L. and B.P.B. designed research; P.W.L. performed research; P.W.L. analyzed data; P.W.L. and B.P.B. wrote the paper.

This work was supported by the National Institutes of Health (Grant NS036855). P.P.L. was partially supported by a fellowship from the Brooks Foundation. We thank Zayd Khaliq for advice and discussion.

The authors declare no competing financial interests.

Correspondence should be addressed to Bruce P. Bean, Harvard Medical School, 220 Longwood Avenue, Boston, MA 02115.E-mail: bruce_bean@hms.harvard.edu.

DOI:10.1523/JNEUROSCI.1925-13.2014

Copyright $\odot 2014$ the authors $\quad 0270-6474 / 14 / 344991-12 \$ 15.00 / 0$
}

2000; Guan et al., 2013), but can contribute significantly to repolarization of wider action potentials in sympathetic neurons (Malin and Nerbonne, 2002). In both CA1 and sympathetic neurons, loss of Kv2 disrupts maintained repetitive or tonic firing ( $\mathrm{Du}$ et al., 2000; Malin and Nerbonne, 2002; Guan et al., 2013), an effect seen also with computer modeling of neuron firing in the medial nucleus of the trapezoid body (Johnston et al., 2008, 2010). The function of $\mathrm{Kv} 2$ channels is of particular interest because of highly plastic expression (Misonou et al., 2005; Nataraj et al., 2010; Fox et al., 2013) and strong modulation by multiple pathways (Mohapatra et al., 2007; Cerda and Trimmer, 2011; Plant et al., 2011; Steinert et al., 2011).

A long-standing problem in studying the function of $\mathrm{Kv} 2$ channels is a lack of a high-selectivity blocker. Hanatoxin and stromatoxin are both effective inhibitors of Kv2 channels, but also potently inhibit Kv4-mediated A-type $\left(I_{\mathrm{A}}\right)$ current (Swartz and MacKinnon, 1995, 1997; Escoubas et al., 2002). Stromatoxin can be used effectively to characterize Kv2 channels in voltage-clamp experiments, where effects on $I_{\mathrm{A}}$ can be minimized using appropriate voltage protocols (Guan et al., 2007). However, the lack of selectivity precludes its use in current-clamp experiments studying excitability, where such strategies are impossible. Recently, Herrington et al. identified a peptide toxin from the venom of the Chinese tarantula Plesiophrictus guangxiensis as a potent inhibitor of Kv2 family channels, with a half-blocking concentration of 2-5 
nм (Herrington et al., 2006; Herrington, 2007). In addition to being more potent than hanatoxin or stromatoxin, this peptide, Guangxitoxin-1E (GxTX-1E) had higher specificity for Kv2 channels, inhibiting Kv4.3 channels with an $\sim 8$-fold lower potency and without significant effect on Kv1 or Kv3 family channels. The high selectivity of GxTX-1E for Kv2 makes it an attractive tool for studying the function of Kv2 channels in various types of neurons. Using GxTX-1E to produce rapid channel block, we used a combination of voltage-clamp and currentclamp recordings to explore the function of Kv2 in regulating action potential repolarization and repetitive firing. We focused on two types of mammalian neurons in which Kv2 channels have been shown previously to be strongly expressed, sympathetic neurons of the superior cervical ganglion (Malin and Nerbonne, 2002) and hippocampal CA1 pyramidal neurons (Du et al., 2000).

\section{Materials and Methods}

Preparation of superior cervical ganglion neurons. Dissociated superior cervical ganglion (SCG) neurons were prepared using enzymatic treatment as described previously (Liu et al., 2012). Briefly, SCG neurons were removed from Sprague Dawley rats of either sex (postnatal day 14-28), cut in half, and treated for $20 \mathrm{~min}$ at $37^{\circ} \mathrm{C}$ with $20 \mathrm{U} / \mathrm{ml}$ papain (Worthington Biochemical) and $5 \mathrm{~mm}$ DL-cysteine in a calcium- and magnesium-free (CMF) Hank's buffer containing the following (in mM): $137 \mathrm{NaCl}, 5.36 \mathrm{KCl}, 0.33 \mathrm{Na}_{2} \mathrm{HP}_{4}, 0.44 \mathrm{KH}_{2} \mathrm{PO}_{4}, 5$ HEPES, 5.55 glucose, along with $0.001 \%$ phenol red, $\mathrm{pH} 7.4$, adjusted with $\mathrm{NaOH}$ at $\sim 300-$ $310 \mathrm{mOsm}$. Ganglia were then treated for $20 \mathrm{~min}$ at $37^{\circ} \mathrm{C}$ with $3 \mathrm{mg} / \mathrm{ml}$ collagenase (type I; Roche Diagnostics) and $4 \mathrm{mg} / \mathrm{ml}$ dispase II (Roche Diagnostics) in CMF Hank's buffer. Cells were dispersed by trituration with a fire-polished glass Pasteur pipette in a solution composed of two media combined in a 1:1 ratio: Leibovitz's L-15 medium (Invitrogen) supplemented with 5 mM HEPES and DMEM/F12 medium (Invitrogen); this solution also contained $100 \mathrm{ng} / \mathrm{ml}$ nerve growth factor (NGF; Invitrogen). Cells were then plated on glass coverslips treated with $40 \mu \mathrm{g} / \mathrm{ml}$ poly-D-lysine and then $20 \mu \mathrm{g} / \mathrm{ml}$ laminin (Invitrogen). Then cells were incubated at $37^{\circ} \mathrm{C}\left(5 \% \mathrm{CO}_{2}\right)$ for $3 \mathrm{~h}$, after which neurobasal medium (Invitrogen) containing B-27 supplement (Invitrogen); penicillin and streptomycin (Sigma); and $100 \mathrm{ng} / \mathrm{ml} \mathrm{NGF}$ was added to the Petri dish. Cells were stored at $4^{\circ} \mathrm{C}$ and used within $48 \mathrm{~h}$.

Preparation of hippocampal CA1 pyramidal neurons. Hippocampal CA1 pyramidal neurons were acutely dissociated from Black Swiss mice of either sex (postnatal day 14-17) as described previously (Raman and Bean, 2001; Carter and Bean, 2009). Animals were anesthetized with isoflurane and the whole brain was quickly removed into ice-cold solution consisting of the following (in mM): $110 \mathrm{NaCl}, 2.5 \mathrm{KCl}, 10$ HEPES, 25 glucose, 75 sucrose, $7.5 \mathrm{MgCl}_{2}, \mathrm{pH}$ adjusted to 7.4 with $\mathrm{NaOH}$. The hippocampi were removed and cut on a tissue chopper into $400 \mu \mathrm{m}$ slices. The CA1 regions were dissected out and treated for 10-20 min at room temperature with $3 \mathrm{mg} / \mathrm{ml}$ protease XXIII (Sigma) dissolved in a dissociation solution consisting of the following (in $\mathrm{mM}$ ): $82 \mathrm{Na}_{2} \mathrm{SO}_{4}, 30$ $\mathrm{K}_{2} \mathrm{SO}_{4}, 5 \mathrm{MgCl}_{2}, 10$ glucose, and 10 HEPES, pH adjusted to 7.4 with $\mathrm{NaOH}$. The protease solution was then replaced by ice-cold dissociation solution containing $1 \mathrm{mg} / \mathrm{ml}$ trypsin inhibitor and $1 \mathrm{mg} / \mathrm{ml}$ bovine serum albumin and the chunks were kept on ice in this solution until immediately before use. To release individual cells, the tissue was passed through Pasteur pipettes with fire-polished tips. A drop of the suspension was placed in the recording chamber and diluted with a large volume of Tyrode's solution consisting of the following (in $\mathrm{mm}$ ): $151 \mathrm{NaCl}, 2.5 \mathrm{KCl}$, $2 \mathrm{CaCl}_{2}, 1 \mathrm{MgCl}_{2}, 10$ HEPES, 13 glucose, $\mathrm{pH}$ adjusted to 7.4 with $\mathrm{NaOH}$. Pyramidal neurons were chosen for recording based on their shape.

Electrophysiology. Recordings were performed at $37^{\circ} \mathrm{C}$ using a Molecular Devices Multiclamp 700B Amplifier. Voltage or current commands were delivered and signals were recorded using a Digidata 1321A data acquisition system (Molecular Devices) controlled by pCLAMP 9.2 software (Molecular Devices). Electrodes were pulled on a Sutter P-97 puller (Sutter Instruments) and shanks were wrapped with Parafilm (American
National Can Company) to allow optimal series resistance compensation without oscillation. The resistances of the pipettes were 1-4 M $\Omega$. Seals were formed in Tyrode's solution consisting of the following (in $\mathrm{mm}$ ): $155 \mathrm{NaCl}, 3.5 \mathrm{KCl}, 1.5 \mathrm{CaCl}_{2}, 1 \mathrm{MgCl}_{2}, 10$ HEPES, 10 glucose, pH 7.4 adjusted with $\mathrm{NaOH}$. After establishing whole-cell recording, cell capacitance was nulled and series resistance was partially (70-85\%) compensated. The cell was then lifted and placed in front of a series of quartz fiber flow pipes attached with cyanoacrylate glue to a rectangular aluminum rod (cross section $1.5 \mathrm{~cm} \times 0.5 \mathrm{~cm}$ ), the temperature of which was controlled to $38^{\circ} \mathrm{C}$ using resistive heating elements and a feedbackcontrolled temperature controller (TC-344B; Warner Instruments). The end of the rod and the flow pipes (extending $1 \mathrm{~mm}$ from the end of the rod) were lowered just to the surface of the bulk chamber solution, which was locally quickly warmed by the rod; with the temperature of the aluminum rod set to $38^{\circ} \mathrm{C}$, the solution exiting from the flow pipes was measured at $37^{\circ} \mathrm{C}$ (Carter and Bean, 2009). All flow pipes were heated identically and continuously, allowing rapid solution changes without fluctuations of temperature. Solutions were changed (in $\sim 1 \mathrm{~s}$ ) by moving the cell from one pipe to another.

Solutions. The standard recording solutions had quasiphysiological ionic composition, with an internal solution consisting of the following (in mM): $140 \mathrm{~K}$ aspartate, $13.5 \mathrm{NaCl}, 1.6 \mathrm{MgCl}_{2}, 0.09$ EGTA, 9 HEPES, 14 creatine phosphate (Tris salt), 4 MgATP, 0.3 Tris-GTP, pH 7.2 adjusted with $\mathrm{KOH}$ and an external Tyrode's solution consisting of the following (in mM): $155 \mathrm{NaCl}, 3.5 \mathrm{KCl}, 1.5 \mathrm{CaCl}_{2}, 1 \mathrm{MgCl}_{2}, 10$ HEPES, 10 glucose, $\mathrm{pH} 7.4$ adjusted with $\mathrm{NaOH}$. For experiments on sodium current and calcium current, the intracellular solution was Cs based and contained the following (in mM): $122 \mathrm{CsCl}, 9 \mathrm{NaCl}, 1.8 \mathrm{MgCl}_{2}, 9$ EGTA, 9 HEPES, 14 creatine phosphate (Tris salt), 4 MgATP, 0.3 Tris-GTP, pH 7.2 adjusted with $\mathrm{CsOH}$; the external solution contained reduced sodium to allow optimal clamp of sodium currents and consisted of the following (in mM): $25 \mathrm{NaCl}, 128.5$ tetraethylammonium (TEA) chloride, $2 \mathrm{CaCl}_{2}, 1$ $\mathrm{MgCl}_{2}, 10$ HEPES, 10 glucose, $\mathrm{pH} 7.4$ adjusted with TEA OH. Synthetic GxTX-1E (Peptide Institute) was made as $100 \mu \mathrm{M}$ stock solutions in distilled $\mathrm{H}_{2} \mathrm{O}$; aliquots were stored at $-20^{\circ} \mathrm{C}$ and diluted immediately before use to minimize oxidation.

Analysis. Current and voltage records were filtered at $5 \mathrm{kHz}$ and digitized at $100 \mathrm{kHz}$. Analysis was performed with Igor Pro 6.12 (Wavemetrics) using DataAccess (Bruxton Software) to import pClamp data. Reported membrane potentials are corrected for a liquid junction potential of $-10 \mathrm{mV}$ between the internal solution and the Tyrode's solution in which current was zeroed before sealing onto the cell, measured using a flowing $3 \mathrm{M} \mathrm{KCl}$ reference electrode as described by Neher (1992). Voltage-clamp current records were corrected for linear capacitative and leak current by subtracting scaled responses to $5 \mathrm{mV}$ hyperpolarizations delivered from the holding potential. For quantification of inhibition of $I_{\mathrm{A}}$ by GxTX-1E, $I_{\mathrm{A}}$ was activated by a step from $-90 \mathrm{mV}$ to $-40 \mathrm{mV}$; to isolate $I_{\mathrm{A}}$, the current evoked by a step from -70 to $-40 \mathrm{mV}$ (a small inward calcium current remaining after inactivation of the much larger $\left.I_{\mathrm{A}}\right)$ was subtracted. In action potential clamp experiments in SCG neurons (de Haas and Vogel, 1989; Blair and Bean, 2002), action potentials were evoked by current injection ( $50 \mathrm{pA}$ for $500 \mathrm{~ms}$ ) and then used as the command waveform in voltage clamp. To measure total net outward current during the repolarization phase of the action potential, the current was integrated from the time that net current under control conditions became net outward (near the peak of the action potential) to the time of the trough after the action potential, when net current under control conditions shifted from outward to inward.

In analyzing action potential waveforms, the upstroke velocity was read at the time of maximal change of voltage on the upstroke, and the downstroke velocity was read at the time of maximal change on the repolarizing phase. The trough voltage was read at the time of the most negative voltage in between two spikes. We use the term "trough" rather than "afterhyperpolarization" because, in some cases, the most negative voltage reached between spikes was still positive to the resting potential.

Series resistance was measured from the decay time constant for the capacity transient for a $5 \mathrm{mV}$ depolarization and then feedback compensation for $70-85 \%$ of the series resistance was applied using the amplifier circuitry while also nulling the cell capacitance. Before compensation, 
average time constant for the capacity transient was $121 \pm 6 \mu$ s for recordings in SCG neurons $(n=65)$ and $72 \pm 5 \mu$ s in CA1 neurons $(n=$ 56); average series resistance was 7.9 $\pm 4 \mathrm{M} \Omega$ in SCG neurons and $6.4 \pm$ $0.4 \mathrm{M} \Omega$ in CA1 neurons. With compensation of $70-85 \%$, the series resistance remaining uncompensated was typically $\sim 1-2.5 \mathrm{M} \Omega$. In cells with particularly large potassium currents activated by strong depolarizations, the remaining series resistance would lead to errors in voltage seen by the membrane and the measurements of the voltage dependence of channel activation and channel kinetics were likely affected somewhat by this error. In principle, the series resistance errors could be reduced by using solutions designed to reduce current magnitudes, but we chose not to do this for several reasons. First, we wanted to characterize the currents by voltage clamp under conditions as near to physiological as possible. Second, any ion that might be used to partially replace intracellular potassium has a risk of partially blocking channels in a voltage-dependent manner, whereas increased external potassium is known to alter gating of many potassium channels. In principle, measurements of current versus voltage curves used to calculate the voltage dependence of channel gating could be corrected to account for residual series resistance errors, but in practice, we found that such correction had only small effects on calculated fits (e.g., changing the fitted midpoint for the activation curve in Fig. $2 B$ by $<1 \mathrm{mV}$ and not affecting the slope factor). These effects were smaller than the cell-to-cell variability seen even in cells with smaller currents, in which series resistance errors were small. Therefore, we did not incorporate such correction in the analysis.

Current sensitive to GxTX-1E was calculated by subtracting traces recorded before and after application of GxTX-1E. Current resistant to GxTX-1E was the leak-corrected current remaining in the presence of GxTX-1E.

Data are given as mean \pm SEM and statistical significance was assessed using a two-tailed Student's $t$ test, paired or unpaired as appropriate.

\section{Results}

GxTX-1E inhibits $\sim 80 \%$ of delayed-rectifier potassium current in SCG neurons

Previous data based on expression of dominant-negative subunits have suggested a prominent role for Kv2 channels in sympathetic neurons in the SCG (Malin and Nerbonne, 2002). Therefore, we first tested the effects of inhibiting Kv2 channels by GxTX-1E in rat SCG neurons. To facilitate optimal space clamp and rapid voltage clamp, we used acutely dissociated SCG neurons. Experiments were done at $37^{\circ} \mathrm{C}$ to explore the kinetics of action potentials and channel gating at a physiological temperature.

Figure $1 A$ shows the effect of GxTX-1E on voltage-activated potassium currents in a rat SCG neuron. Application of $100 \mathrm{~nm}$ GxTX-1E dramatically inhibited delayed rectifier current and 200 nM GXTX-1E had little further effect. Inhibition of delayedrectifier current by GxTX-1E revealed a prominent inactivating current (Fig. 1A), as expected from the presence of substantial $I_{\mathrm{A}}$ in SCG neurons (Malin and Nerbonne, 2001, 2002). Consistent with representing $I_{\mathrm{A}}$, the inactivating current remaining in GxTX-1E was eliminated nearly completely by a holding potential of $-70 \mathrm{mV}$ (Fig. 1A, right). In contrast, the delayed-rectifier current sensitive to GxTX-1E was little different from a holding potential of $-70 \mathrm{mV}$ compared with $-90 \mathrm{mV}$.

Figure $1 B$ shows the effect of GxTX-1E on the voltage dependence of peak outward current during $200 \mathrm{~ms}$ pulses delivered from $-90 \mathrm{mV}$. Of the component sensitive to GxTX-1E, corresponding to a relatively slowly activating, maintained current, 100 nM GxTX-1E seemed to produce nearly saturating effects, because 200 nM GxTX-1E had very little additional effect. In collected results, $100 \mathrm{~nm}$ GxTX-1E inhibited peak outward current for a step from $-90 \mathrm{mV}$ to $+30 \mathrm{mV}$ to $49 \pm 6 \%$ of control $(n=$ 10) and increasing the concentration to $200 \mathrm{~nm}$ had no further

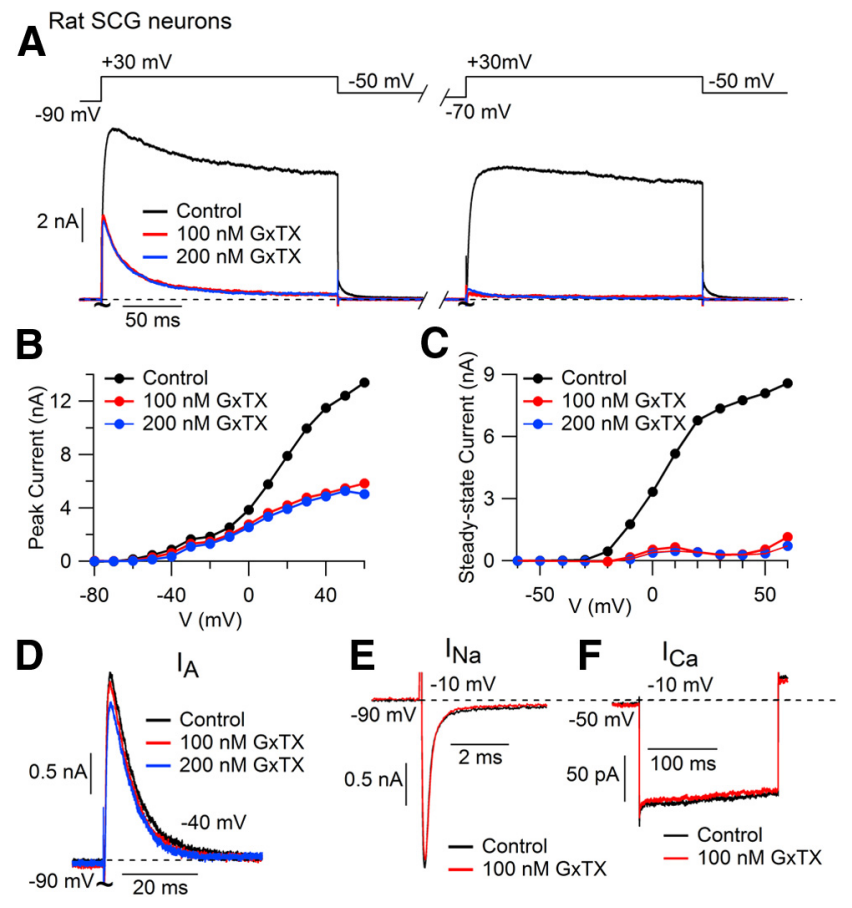

Figure 1. Effect of GxTX-1E on voltage-activated currents in rat SCG neurons. A, Effect of 100 and $200 \mathrm{~nm}$ GXTX-1E on outward currents in a rat SCG neuron evoked by steps from $-90 \mathrm{mV}$ to $+30 \mathrm{mV}$ (left) and $-70 \mathrm{mV}$ to $+30 \mathrm{mV}$ (right). The membrane was held at $-70 \mathrm{mV}$ for $1 \mathrm{~s}$ between the two steps to $+30 \mathrm{mV}$. $\boldsymbol{B}$, Effect of 100 and $200 \mathrm{~nm}$ GxTX-1E on peak outward current evoked from $-90 \mathrm{mV}$ (same cell as in $\boldsymbol{A}$ ). C, Effect of 100 and $200 \mathrm{~nm}$ GxTX-1E on steady-state outward current (measured at the end of $200 \mathrm{~ms}$ steps) evoked from $-90 \mathrm{mV}$ (same cell as in $\boldsymbol{A}, \boldsymbol{B}$ ). $\boldsymbol{D}$, Effect of $G x T X-1 E$ on $I_{\mathrm{A}}$ evoked by a step from -90 to $-40 \mathrm{mV}$. $\boldsymbol{E}$, Effect of GXTX-1E on sodium current evoked by a step from $-90 \mathrm{mV}$ to $-10 \mathrm{mV}$. Recording made with internal Cs-based solution and external solution containing $25 \mathrm{~mm} \mathrm{NaCl}, 2 \mathrm{~mm} \mathrm{CaCl}$, and 128.5 TEA Cl. Initial fast sodium current is followed by a small sustained calcium current. $\boldsymbol{F}$, Calcium current evoked by a step from $-50 \mathrm{mV}$ to $-10 \mathrm{mV}$ before and after application of 100 nм GXTX-1E. Same solutions as in $\boldsymbol{E}$; cell was held at $-50 \mathrm{mV}$ to inactivate sodium current.

effect (reduction to $51 \pm 7 \%$ of control, $n=10 ; p=0.80$ between 100 and $200 \mathrm{nM}$ ). In absolute terms, control peak current at +30 $\mathrm{mV}$ was $9.7 \pm 1.3 \mathrm{nA}$, peak current in $100 \mathrm{nM} \mathrm{GxTX}-1 \mathrm{E}$ was $4.8 \pm$ $0.9 \mathrm{nA}$, and peak current in $200 \mathrm{nM}$ GxTX-1E was $5.0 \pm 1.0 \mathrm{nA}$ $(n=10)$.

As evident in the traces in Figure $1 A$, the peak current remaining in GxTX-1E corresponded mainly to $I_{\mathrm{A}}$. Accordingly, the effect of GxTX-1E on steady-state current at the end of $200 \mathrm{~ms}$ steps, when $I_{\mathrm{A}}$ had inactivated, was much more complete (Fig. $1 C)$. Steady-state outward current for a step from $-90 \mathrm{mV}$ to $+30 \mathrm{mV}$ (initially $7.6 \pm 1.5 \mathrm{nA}$ ) was inhibited to $19 \pm 8 \%$ of control by $100 \mathrm{~nm} \mathrm{GxTX}-1 \mathrm{E}(n=10)$ and to $16 \pm 7 \%$ of control by $200 \mathrm{~nm} \operatorname{GxTX}-1 \mathrm{E}(n=10, p=0.82$ between 100 and $200 \mathrm{~nm})$.

\section{Selectivity of GxTX-1E}

In the experiment shown in Figure $1 A$, the $I_{\mathrm{A}}$ at $+30 \mathrm{mV}$ that remained in $100 \mathrm{nM}$ GxTX-1E was little affected by increasing the concentration of GxTX-1E to $200 \mathrm{nM}$, suggesting that the sensitivity of $I_{\mathrm{A}}$ to GxTX-1E must be quite weak. We tested the sensitivity of $I_{\mathrm{A}}$ to GxTX-1E more directly using steps from $-90 \mathrm{mV}$ to $-40 \mathrm{mV}$ for which rapidly inactivating $I_{\mathrm{A}}$ comprised almost all the outward current (Fig. 1D). GxTX-1E had a weak blocking effect, reducing peak $I_{\mathrm{A}}$ by $8 \pm 4 \%$ at $100 \mathrm{nM} \mathrm{GxTX}-1 \mathrm{E}(n=9)$ and by $19 \pm 8 \%$ at $200 \mathrm{~nm} \operatorname{GxTX}-1 \mathrm{E}(n=9)$. Therefore, $100 \mathrm{~nm}$ GxTX-1E appears to produce nearly saturating effects on Kv2 current in rat SCG neurons while inhibiting $I_{\mathrm{A}}$ relatively little. 
Rat SCG neurons
A
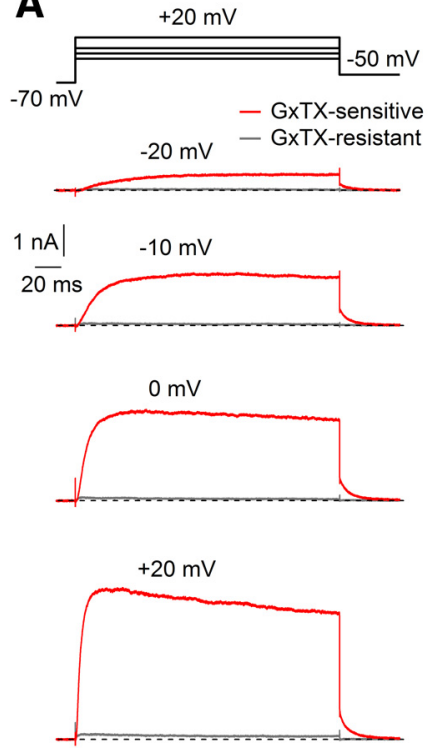

B
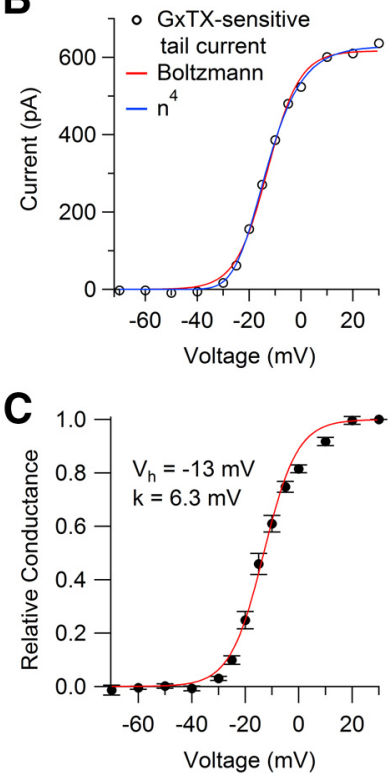

Figure 2. Voltage dependence of Kv2 current determined by GXTX subtraction in rat SCG neurons. $\boldsymbol{A}$, GxTX-sensitive current determined by subtracting currents recorded before and after applying $200 \mathrm{~nm}$ GXTX-1E. Solution contained $1 \mu \mathrm{m}$ TTX, $1 \mu \mathrm{m} \omega$-conotoxin GVIA, and $1 \mathrm{~mm}$ TEA. $\boldsymbol{B}$, Voltage dependence of activation of GXTX-sensitive current determined by plotting tail current at $-50 \mathrm{mV}$ as a function of the test voltage. Solid red line, Fit to simple Boltzmann function $1 /\left(1+\exp -\left(V-V_{h}\right) / k\right)$, where $V_{h}=-12.9 \mathrm{mV}$ is the midpoint and $k=6.2 \mathrm{mV}$ is the slope factor. Solid blue line: fit to a Boltzmann function raised to fourth power, $[1 /(1+$ $\left.\left.\exp -\left(V-V_{\mathrm{hn}}\right) / k_{\mathrm{n}}\right)\right]^{4}$, where $V_{\mathrm{hn}}=-27.4 \mathrm{mV}$ is the voltage at which half of the $n$ particles are in the activated position and $k_{\mathrm{n}}=8.6 \mathrm{mV}$ is the slope factor for activation of $n$ particles. $\boldsymbol{C}$, Mean \pm SEM for normalized conductance determined by tail current activation curves in SCG neurons $(n=7)$. Solid red line: simple Boltzmann function $1 /\left(1+\exp -\left(V-V_{h}\right) / k\right)$, where $V_{\mathrm{h}}=-13.1 \mathrm{mV}$ and $k=6.3 \mathrm{mV}$ are mean values of results of separate fits in each of 7 cells (SEM values of 0.9 and $0.1 \mathrm{mV}$, respectively).

At $100 \mathrm{~nm}$, application of GxTX-1E to rat SCG neurons had a small effect on sodium current (Fig. $1 E$ ) and none on calcium current (Fig. $1 F)$. On average, there was a $7 \pm 1 \%$ reduction in sodium current by $100 \mathrm{~nm}$ GxTX-1E $(n=7)$. There was no discernible effect on calcium current $(n=6)$ when taking into account slow run-down of calcium current seen even in the absence of toxin application.

\section{Voltage dependence of Kv2 current in SCG neurons}

We used block by GxTX-1E to define the voltage dependence and kinetics of Kv2 current in SCG neurons. Figure 2 illustrates the voltage dependence of Kv2 current. Detectable current was first activated at voltages between -30 and $-25 \mathrm{mV}$. To define the voltage dependence of steady-state activation, we constructed activation curves using tail currents after $200 \mathrm{~ms}$ pulses (Fig. 2B). The experimental data could be fit reasonably well by a simple Boltzmann curve with a midpoint of $12.9 \mathrm{mV}$ and a slope factor of $6.2 \mathrm{mV}$ (Fig. $2 B$, red line). However, the voltage dependence of activation could be fit better by a Boltzmann function raised to the fourth power (blue line), which is consistent with the expectation that opening of channels requires movement of the S4 segments of four subunits and with the classic Hodgkin-Huxley description of voltage dependence of potassium current in the squid giant axon as governed by four independent " $n$ " gates, each obeying a Boltzmann distribution (Hodgkin and Huxley, 1952).

The voltage dependence of Kv2 current as defined by GxTX-1E subtraction was highly consistent from cell to cell. Fig-
Rat SCG neurons
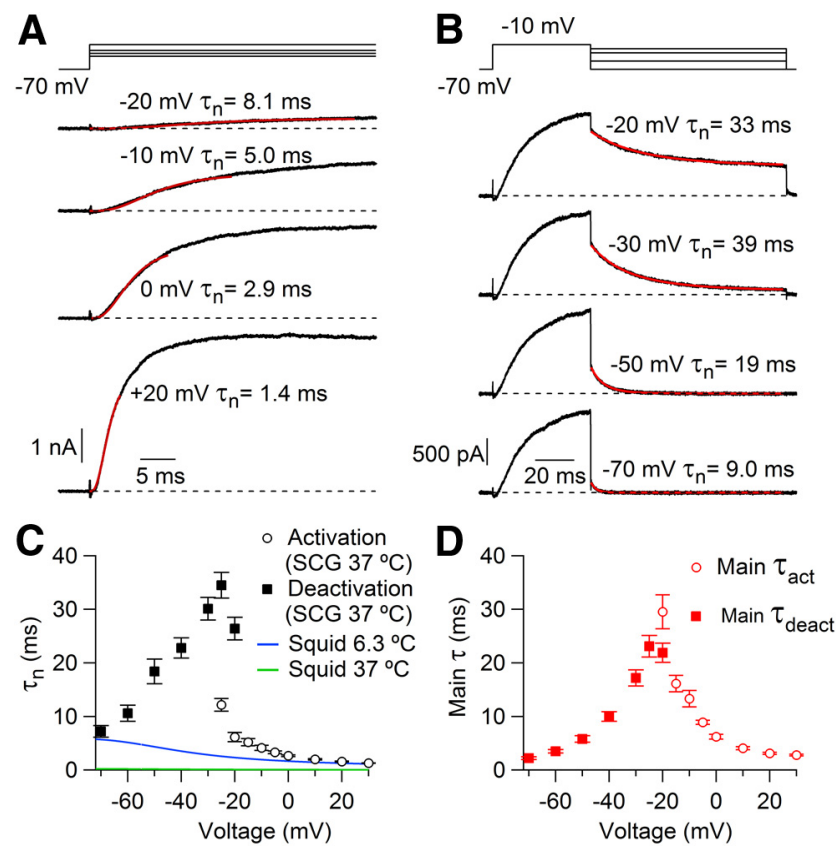

Figure 3. Activation and deactivation kinetics of Kv2 current in rat SCG neurons. A, Activation kinetics of Kv2 current isolated by GxTX subtraction as in Figure 2. Activation was fit by $n^{4}$ kinetics, $A\left[1-\exp \left(-t / \tau_{\mathrm{n}}\right)\right]^{4}$, where $A$ is steady-state amplitude and $\tau_{\mathrm{n}}$ is the time constant for $n$ particle gating. Fits are shown as red lines. $B$, Kinetics of deactivation. Red lines show fits to $n^{4}$ kinetics, $\left.A\left[n_{\infty-}\left(n_{\infty}-n_{0}\right) \exp \left(-t / \tau_{n}\right)\right)\right]^{4}$, where $A$ is an amplitude factor, $n_{0}$ and $n_{\infty}$ are the starting and final values of $n$, respectively, and $\tau_{\mathrm{n}}$ is the time constant for $n$ particle gating. $C, \tau_{\mathrm{n}}$ as a function of voltage. Mean \pm SEM for determinations in seven cells for activation (open circles) and seven cells for deactivation (filled squares). Blue line, $\tau_{\mathrm{n}}$ for delayed-rectifier current in squid axon at $6.3^{\circ} \mathrm{C}$ from Hodgkin-Huxley equations (Hodgkin and Huxley, 1952). Green line, $\tau_{\mathrm{n}}$ for delayed-rectifier current in squid axon at $37^{\circ} \mathrm{C}$ calculated using a $Q_{10}$ of 3 . D, Dominant time constants for activation (open circles) and deactivation (filled squares) in SCG neurons obtained by fitting the major relaxation of current by a single exponential. Activation was fit starting at $35 \%$ of the rise (to avoid the lag) and deactivation was fit to the final $80 \%$ of the decay.

ure $2 C$ shows an activation curve constructed from averaged data in seven SCG neurons. The results were quite consistent over cells and the voltage dependence of the collected data was described fairly well by a simple Boltzmann curve constructed from the averaged midpoints and slope factors of the individual cells, with a midpoint of $-13.1 \pm 0.9 \mathrm{mV}$ and slope factor of $6.3 \pm 0.1 \mathrm{mV}$ $(n=7)$. When fit by an $n^{4}$ scheme, the midpoint for activation of the $n$ particles $\left(V_{\mathrm{hn}}\right)$ was $-27.6 \pm 0.8 \mathrm{mV}$ and the slope factor $\left(k_{\mathrm{n}}\right)$ was $8.6 \pm 0.1 \mathrm{mV}(n=7)$. The midpoint for channel opening (which for $n^{4}$ behavior corresponds to $V_{\mathrm{hn}}+1.665 k_{\mathrm{n}}$ ) calculated from the $n^{4}$ fits was $-13.3 \pm 0.9 \mathrm{mV}(n=7)$, very close to the midpoint of the averaged data from simple Boltzmann fits.

Figure 3 shows the kinetics of Kv2 current as defined by GxTX-subtraction. Just as for potassium current in the squid giant axon, Kv2 current in SCG neurons activated with a pronounced sigmoidicity and the delay in opening could be fit well by $n^{4}$ kinetics (Fig. $3 A$ ). Fits by $n^{4}$ kinetics were very good when confined to the first $60-70 \%$ of the rising phase of the current, but the fit to the final $30-40 \%$ was not perfect. This deviation from simple $n^{4}$ kinetics may reflect the existence of a concerted final opening step required after all four S4 segments have activated, as proposed for Shaker potassium channels (Schoppa and Sigworth, 1998). Another deviation from $n^{4}$ kinetics was that time constants derived from activation were much less than time constants derived from deactivation at the same voltage (Fig. $3 C$ ). 
For example, at $-20 \mathrm{mV}, \tau_{\mathrm{n}}$ from activation fits was $6.1 \pm 0.9 \mathrm{~ms}$, whereas $\tau_{\mathrm{n}}$ from deactivation was $26.4 \pm 2.1 \mathrm{~ms}(n=7)$. This deviation from $n^{4}$ kinetics may also reflect a concerted final and closing step. Therefore, although $n^{4}$ kinetics are useful for capturing the sigmoidicity of channel opening, they are likely not optimal for describing deactivation. We therefore also analyzed the kinetics of activation and deactivation in a less modeldependent manner by fitting single time constants to the main components of relaxations in activation and deactivation (Fig. $3 D$ ), ignoring the initial lag in activation. Here, there was much closer correspondence between activation and deactivation time constants (at $-20 \mathrm{mV}, \tau_{\text {act }}=29.5 \pm 32 \mathrm{~ms}, \tau_{\text {deact }}=21.9 \pm 1.8$ ms; Fig. 3D).

Computational models for the electrical behavior of neurons often begin by using conductances based on the Hodgkin-Huxley equations for gating of sodium and potassium channels in the squid axon. It is striking how much slower the dominant delayedrectifier potassium current in rat SCG neurons is compared with the delayed-rectifier current in the squid axon. In fact, as shown by the comparison in Figure $3 C$, the kinetics of $\mathrm{Kv} 2$ current in rat SCG neurons recorded at $37^{\circ} \mathrm{C}$ are slower (e.g., $\tau_{\mathrm{n}}$ of $4.1 \pm 0.5 \mathrm{~ms}$ at $-10 \mathrm{mV}$ ) than potassium current in the squid axon recorded near $6^{\circ} \mathrm{C}\left(\tau_{\mathrm{n}}\right.$ of $1.9 \mathrm{~ms}$ at $\left.-10 \mathrm{mV}\right)$. The difference is even more dramatic when compared with squid current rates adjusted to $37^{\circ} \mathrm{C}$ with a $Q_{10}$ of $3\left(\tau_{\mathrm{n}}\right.$ of $66 \mu \mathrm{s}$ at $\left.-10 \mathrm{mV}\right)$.

\section{Effects of GxTX-1E on action potentials and repetitive firing in SCG neurons}

We next used GxTX-1E to explore the contribution of Kv2 channels to action potential repolarization and repetitive firing in SCG neurons. Injection of a $50 \mathrm{pA}$ current for $500 \mathrm{~ms}$ elicited repetitive firing that was maintained throughout the current injection, with an average frequency of approximately $40 \mathrm{~Hz}$ (Fig. $4 A$ ). Inhibition of Kv2 channels with $100 \mathrm{~nm}$ GxTX-1E had no effect on the rising phase of the first action potential or its peak, but produced widening of the action potential and a substantial reduction in the trough voltage reached after the first spike before depolarization to the second spike began. In collected results (Fig. $4 B$ ), the first spike broadened by an average of $38 \pm 5 \%$, from $2.12 \pm 0.08 \mathrm{~ms}$ in control to $2.94 \pm 0.17 \mathrm{~ms}$ in $100 \mathrm{~nm}$ GxTX-1E $\left(n=26 ; p=1.7 \times 10^{-7}\right)$, showing that Kv2 current plays an important role in action potential repolarization in SCG neurons at physiological temperature. The broadening of the action potential was accompanied by a reduction in the maximum downstroke velocity of the falling phase, which corresponds to the maximum outward current flowing during the falling phase. On average, the maximum downstroke velocity decreased by $25 \pm$ $2 \%$, from $55.4 \pm 1.8 \mathrm{mV} / \mathrm{ms}$ in control to $41.8 \pm 2.2 \mathrm{mV} / \mathrm{ms}$ in 100 nM GxTX-1E $\left(n=26 ; p=2.2 \times 10^{-9}\right)$. However, the most dramatic effect of blocking Kv2 channels with GxTX-1E was a depolarizing shift of the trough after the first action potential (Fig. $4 A, E$ ), which depolarized by an average of $9.2 \pm 1.3 \mathrm{mV}$, from $-64.5 \pm 0.8 \mathrm{mV}$ in control to $-55.3 \pm 1.6 \mathrm{mV}$ in $100 \mathrm{nM}$ GxTX-1E $\left(n=26, p=9 \times 10^{-8}\right)$.

In some SCG neurons, such as the one shown in Figure $4 A$, blocking Kv2 channels produced an increase in the initial frequency of firing (Fig. 4C), as might be expected from block of a potassium conductance that helps to deepen the afterhyperpolarization. However, this was not seen in all neurons and, on average, the initial firing rate for a $50 \mathrm{pA}$ current injection increased only slightly, from $40.7 \pm 1.5 \mathrm{~Hz}$ in control to $43.7 \pm 2.0 \mathrm{~Hz}$ in $100 \mathrm{~nm}$ GxTX-1E $(n=26, p=0.005)$. By itself, the reduction in Kv2 current during the falling phase and the resulting depolar-
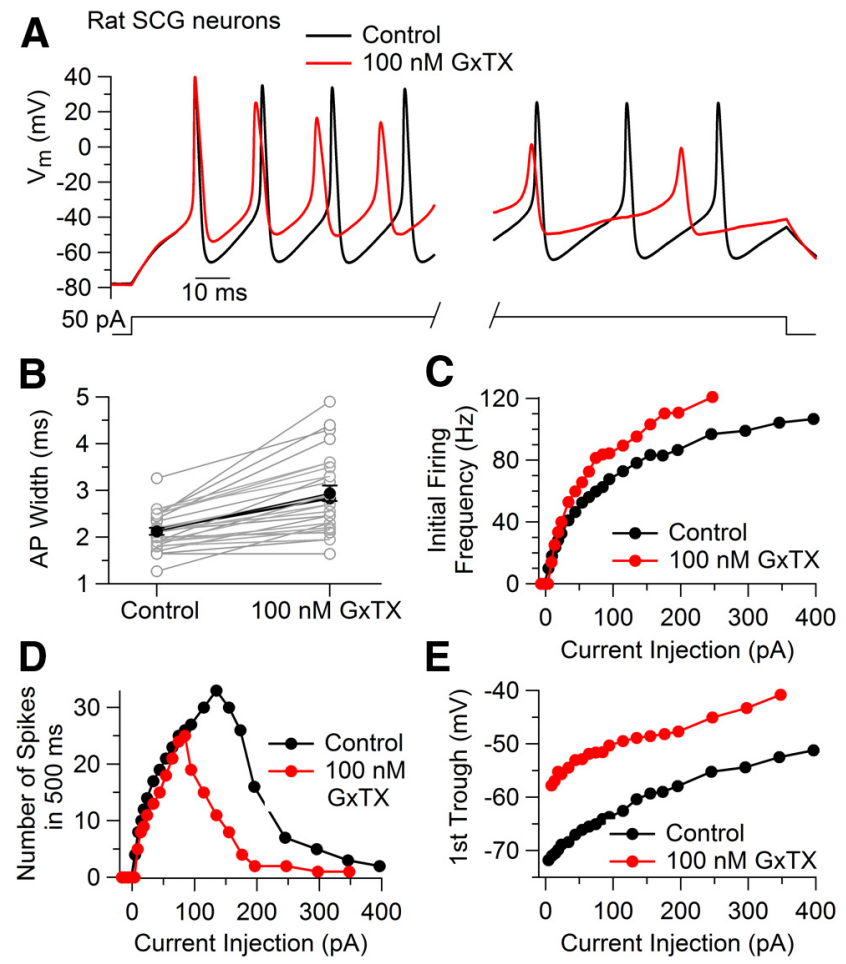

Figure 4. Effect of GXTX-1E on repetitive action potential firing in a rat SCG neuron. $A$, Effect of $100 \mathrm{~nm}$ GXTX-1E on firing evoked by a $500 \mathrm{~ms} 50$ pA current injection. $\boldsymbol{B}$, Effect of $100 \mathrm{~nm}$ GXTX-1E on the width of the first action potential (measured at midpoint) during firing evoked by $50 \mathrm{pA}$ current injections. Connected gray circles show changes in individual cells; connected black circles show mean values \pm SEM. Average spike width was $2.12 \pm 0.08 \mathrm{~ms}$ in control and $2.94 \pm 0.17 \mathrm{~ms}$ in $100 \mathrm{~nm}$ GxTX-1E $\left(n=26 ; p=1.7 \times 10^{-7}\right)$. C, Effect of $100 \mathrm{~nm}$ GXTX-1E on initial firing frequency (measured from first two spikes) for $500 \mathrm{~ms}$ current injections. D, Effect of $100 \mathrm{~nm}$ GXTX-1E on number of spikes (defined as having amplitude $>40 \mathrm{mV}$ ) in the $500 \mathrm{~ms}$ current injection period. $E$, Effect of $100 \mathrm{~nm}$ GXTX-1E on membrane potential of the first trough.

ization of the trough voltage after the first spike would be expected to speed the excitation of the second action potential. However, the depolarization of the trough voltage could also result in reduced recovery of sodium channels from inactivation, which would limit the sodium current able to contribute to the rising phase of the second spike and therefore could result in slowed firing. Apparently, in most SCG neurons, these counteracting effects more or less offset each other during the first interspike interval so that initial firing frequency did not change much. Consistent with a substantial reduction in sodium current during the second spike, the maximum upstroke velocity of the second spike was reduced by $41 \pm 4 \%$, from $194 \pm 9 \mathrm{mV} / \mathrm{ms}$ in control to $115 \pm 10 \mathrm{mV} / \mathrm{ms}$ in $100 \mathrm{~nm} \mathrm{GxTX}-1 \mathrm{E}(n=26 ; p=1 \times$ $\left.10^{-9}\right)$. This decline is in contrast to the upstroke velocity of the first spike, which was essentially unchanged by GxTX-1E (272 \pm $12 \mathrm{mV} / \mathrm{ms}$ in control and $268 \pm 13 \mathrm{mV} / \mathrm{ms}$ in $100 \mathrm{nM} \mathrm{GxTX}-1 \mathrm{E}$; $n=26 ; p=0.2$ ).

Action potentials and firing rate were affected much more strongly by GxTX-1E at later times during repetitive firing. In the example shown in Figure $4 A$, although firing in the presence of GxTX-1E was faster at the beginning of the $500 \mathrm{~ms}$ stimulation period, it was substantially slower than control at the end of the stimulation. In collected results, the firing frequency during the last $200 \mathrm{~ms}$ of a $50 \mathrm{pA} 500 \mathrm{~ms}$ stimulation was reduced by $34 \pm$ $7 \%$, from $33 \pm 11 \mathrm{~Hz}$ in control to $22 \pm 3 \mathrm{~Hz}$ in $100 \mathrm{~nm}$ GxTX-1E $(n=26 ; p=0.00013)$. This reduction in maintained firing frequency by GxTX-1E can likely be attributed to reduction in avail- 
able sodium current as a result of progressively more depolarized interspike intervals. As noted, even after the first spike, the trough voltage in $100 \mathrm{~nm}$ GxTX-1E was depolarized relative to control by $9.2 \pm 1.3 \mathrm{mV}$ (from $-64.5 \pm 0.8 \mathrm{mV}$ to $-55.3 \pm 1.6 \mathrm{mV}$ ) and this effect was somewhat greater in subsequent interspike intervals (in the third interspike interval, depolarization by $11.5 \pm 1.3$ $\mathrm{mV}$ from $-63.2 \pm 0.9 \mathrm{mV}$ in control to $-51.6 \pm 1.6 \mathrm{mV}$ in GxTX-1E and in the fifth interspike interval, by $12.1 \pm 1.2 \mathrm{mV}$ from $-62.6 \pm 0.9 \mathrm{mV}$ in control to $-50.5 \pm 1.5 \mathrm{mV}$ in GxTX1E). This effect continued throughout the $500 \mathrm{~ms}$ stimulation period and the trough voltage preceding the last spike in the series was depolarized by $11.4 \pm 1.2 \mathrm{mV}$, from $-60.1 \pm 1.0 \mathrm{mV}$ in control to $-48.7 \pm 1.4 \mathrm{mV}$ in $100 \mathrm{nM}$ GxTX-1E $(n=26 ; p=$ $6.2 \times 10^{-10}$ ). Consistent with this maintained depolarization of interspike voltages leading to inactivation of sodium channels, the maximum upstroke velocity of the last spike was reduced by $63 \pm 4 \%$, from $106 \pm 9 \mathrm{mV} / \mathrm{ms}$ in control to $39 \pm 5 \mathrm{mV} / \mathrm{ms}$ in 100 nм GxTX-1E $\left(n=26 ; p=3.3 \times 10^{-8}\right)$.

These results suggest that the ability to maintain repetitive firing of full-blown action potentials is reduced after block of Kv2 channels as a consequence of more depolarized voltages between spikes, which in turn results in less recovery from inactivation of sodium channels. This behavior was especially pronounced for larger current injections in which, after blocking of Kv2 channels, the ability to maintain firing during a $500 \mathrm{~ms}$ current injection was greatly reduced as a consequence of cells entering depolarization block. The total number of spikes firing during the $500 \mathrm{~ms}$ stimulation period dropped sharply in the presence of GxTX-1E for large current injections (Fig. $4 D$ ). In collected results, the maximum number of spikes that could be stimulated by any size current injection during a $500 \mathrm{~ms}$ stimulation period was reduced by $42 \pm 5 \%$, from $27 \pm 2$ spikes in control to $17 \pm 2$ spikes in 100 nM GxTX-1E $\left(n=28 ; p=9.9 \times 10^{-10}\right)$, and the magnitude of the current injection at which the maximum spiking occurred was reduced from $154 \pm 22 \mathrm{pA}$ in control to $68 \pm 10 \mathrm{pA}$ with GxTX-1E $\left(n=28, p=9.7 \times 10^{-7}\right)$, reflecting an increased propensity to go into depolarization block and stop firing.

The broadening of action potentials in SCG neurons when Kv2 channels are blocked shows a contribution of Kv2 channels to repolarization, but does not allow an estimate of their relative contribution to the overall potassium current that repolarizes the action potential. This is because even a modest broadening of the action potential when Kv2 channels are blocked could result in a large enhancement of current carried by other types of potassium channels. To quantify the contribution of Kv2 channels to ionic currents during action potentials, we did voltage-clamp experiments in which each cell's own action potentials were recorded and used as the command waveform (Blair and Bean, 2002). We found that 100 nM GxTX-1E dramatically inhibited the outward current during the repolarization phase of action potentials (Fig. 5). The component of total current sensitive to GxTX-1E during the action potential had a larger peak $(501 \pm 44 \mathrm{pA})$ than the current resistant to GxTX-1E ( $363 \pm 46 \mathrm{pA}, n=7)$. The GxTXsensitive current reached a peak later in the repolarization phase than the GxTX-resistant current (Fig. 5B). In collected results, the GxTX-resistant current reached a peak at a voltage of $+23 \pm$ $2 \mathrm{mV}$, early in the repolarization phase, whereas the GxTXsensitive current reached a peak later in the repolarization, at a voltage of $-1 \pm 4 \mathrm{mV}(n=7)$.

These experiments also showed that the relative contribution of Kv2 current to action potential repolarization becomes progressively greater in later action potentials during repetitive firing (Fig. 5B). On average, GxTX-sensitive current comprised $57 \pm$
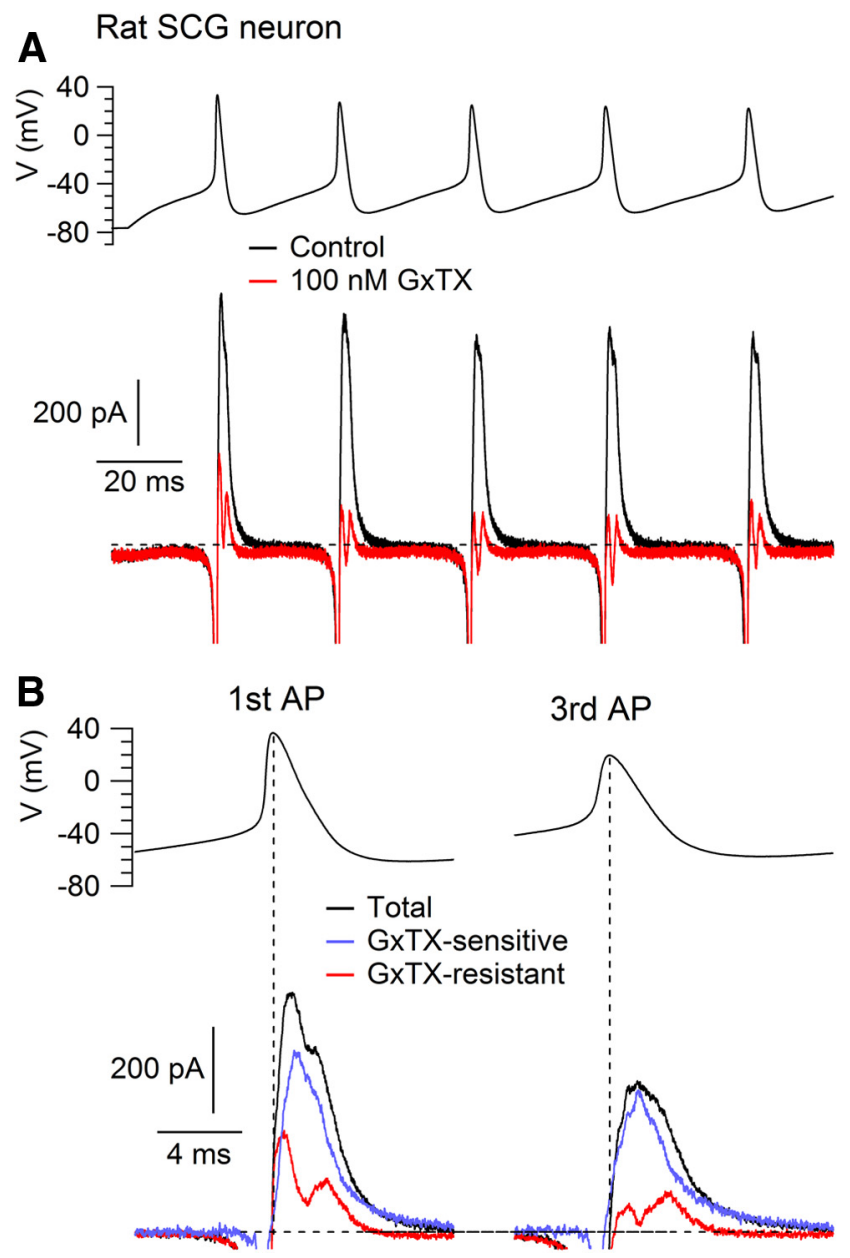

Figure 5. Effect of GXTX-1E on ionic currents during action potentials in a rat SCG neuron. $A$ Effect of $100 \mathrm{~nm}$ GXTX-1E on ionic currents evoked by action potential waveforms in voltageclamp mode. Firing in response to a current injection of $50 \mathrm{pA}$ was recorded and then used as the command waveform in voltage clamp. Current evoked by the waveform was signal averaged over four sweeps before (black) and after (red) application of $100 \mathrm{~nm}$ GXTX-1E. Capacitative current was nulled using the capacity compensation circuitry of the amplifier. $\boldsymbol{B}$, Action potential-evoked currents for the first (left) and third (right) action potentials shown at faster time base. Inward sodium currents are truncated. Black, Before application of GXTX-1E. Red, After GXTX-1E. Blue, Point by point subtraction of before-after to obtain GxTX-sensitive current.

$5 \%$ of the total outward current during the falling phase of the first action potential evoked by a current injection, $68 \pm 7 \%$ of the third action potential, and $70 \pm 4 \%$ of the fifth action potential $(n=7)$. The greater relative contribution to later action potentials might reflect less susceptibility of Kv2 current to inactivation than GxTX-resistant current, which decreased substantially in the second and succeeding spikes. However, it is notable that, despite its slow activation kinetics, Kv2 current comprises the majority of overall outward current even during the first action potential. This is consistent with the large depolarizing shift of the trough voltage after the first spike seen in the current-clamp experiments.

\section{GxTX-1E inhibits most delayed-rectifier potassium current in} hippocampal CA1 neurons

Kv2 channels are prominently expressed in central neurons and knock-down experiments using antisense and dominantnegative strategies suggest that they contribute a major portion of the overall delayed-rectifier current in hippocampal and cortical pyramidal neurons (Du et al., 2000; Guan et al., 2007, 2011, 
Mouse Hippocampal CA1 Neurons

A
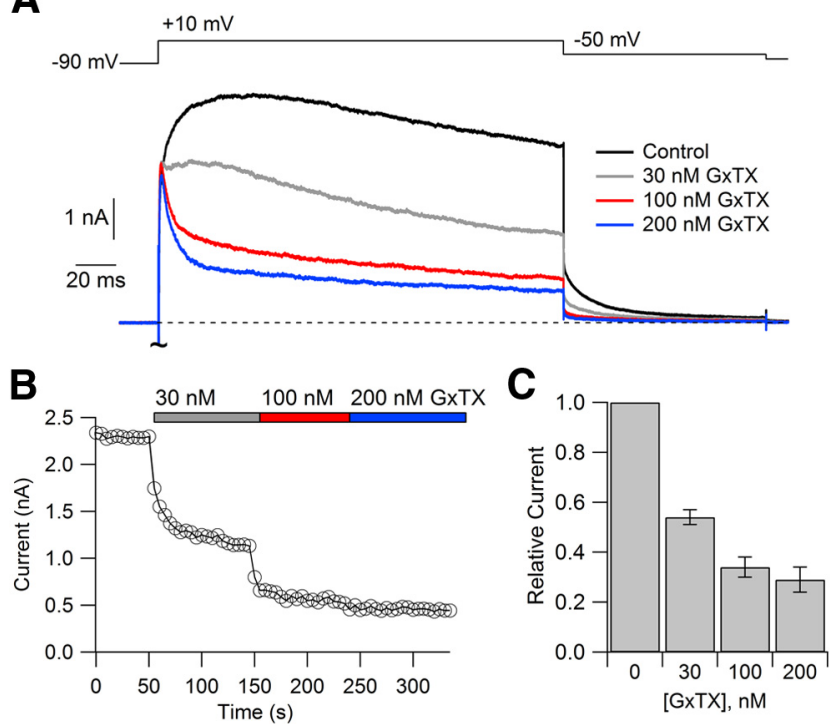

Figure 6. Effect of GXTX-1E on voltage-activated outward currents in mouse hippocampal CA1 neurons. $\boldsymbol{A}$, Effect of 30, 100, and $200 \mathrm{~nm}$ GxTX-1E on currents evoked by a step from $-90 \mathrm{mV}$ to $+10 \mathrm{mV}$. $\boldsymbol{B}$, Time course of inhibition. Current was measured at the end of a 200 ms step to $+10 \mathrm{mV}$ as in $\boldsymbol{A}$. C, Collected results for inhibition of current evoked by a step from $-90 \mathrm{mV}$ to $+10 \mathrm{mV}$ (mean \pm SEM, $n=11$ for $30 \mathrm{~nm} \mathrm{GxTX}-1 \mathrm{E}, n=10$ for 100 and $200 \mathrm{~nm}$ GXTX-1E; $p<10^{-6}$ for all concentrations relative to control; $p=0.02$ for difference between 100 and $200 \mathrm{~nm}$ ).

2013). These studies found that loss of Kv2 current reduced the ability of the neurons to fire repetitively (Du et al., 2000; Guan et al., 2013), but had little effect on the repolarization of single action potentials, as if Kv2 channels activate too slowly to participate in spike repolarization. However, acute block by an agent such as GxTX-1E offers a much more sensitive test of the role of Kv2 channels because it allows direct comparison of spiking behavior in the same cell before and immediately after blocking the channels, unlike population studies with long-term reduction of channel expression, in which it is hard to rule out the possibility of compensatory changes in expression of other channel types. We therefore tested the effect of GxTX-1E on potassium currents and spiking behavior in CA1 pyramidal neurons, again using a preparation of acutely dissociated neurons and making recordings at $37^{\circ} \mathrm{C}$.

We first characterized the effects of GxTX-1E on total potassium current in CA1 pyramidal neurons. GxTX-1E inhibited depolarization-induced outward current in a concentrationdependent manner that showed saturation as the toxin concentration was increased (Fig. $6 A, B$ ). Outward current at the end of a $200 \mathrm{~ms}$ depolarization from $-90 \mathrm{mV}$ to $+10 \mathrm{mV}$ was reduced to $54 \pm 3 \%$ of control by $30 \mathrm{nM} \mathrm{GxTX}-1 \mathrm{E}(n=11)$, to $34 \pm 4 \%$ of control by $100 \mathrm{~nm} \mathrm{GxTX}-1 \mathrm{E}(n=10)$, and to $29 \pm 5 \%$ of control by $200 \mathrm{nM}$ GxTX-1E $\left(n=10 ; p<10^{-6}\right.$ for all concentrations relative to control; $p=0.02$ for difference between 100 and 200 nM; Fig. $6 C$ ). Therefore, $\sim 70 \%$ of the total maintained outward current is blocked by GxTX-1E in a saturating manner, with 100 nM toxin producing a near-saturating effect. The block of a majority of the potassium current in CA1 neurons is consistent with a previous report that Kv2.1 underlies the major component of the delayed-rectifier potassium currents in cultured hippocampal neurons (Murakoshi and Trimmer, 1999).

The components of current sensitive and resistant to GxTX-1E had very different kinetics. As expected for Kv2 cur-
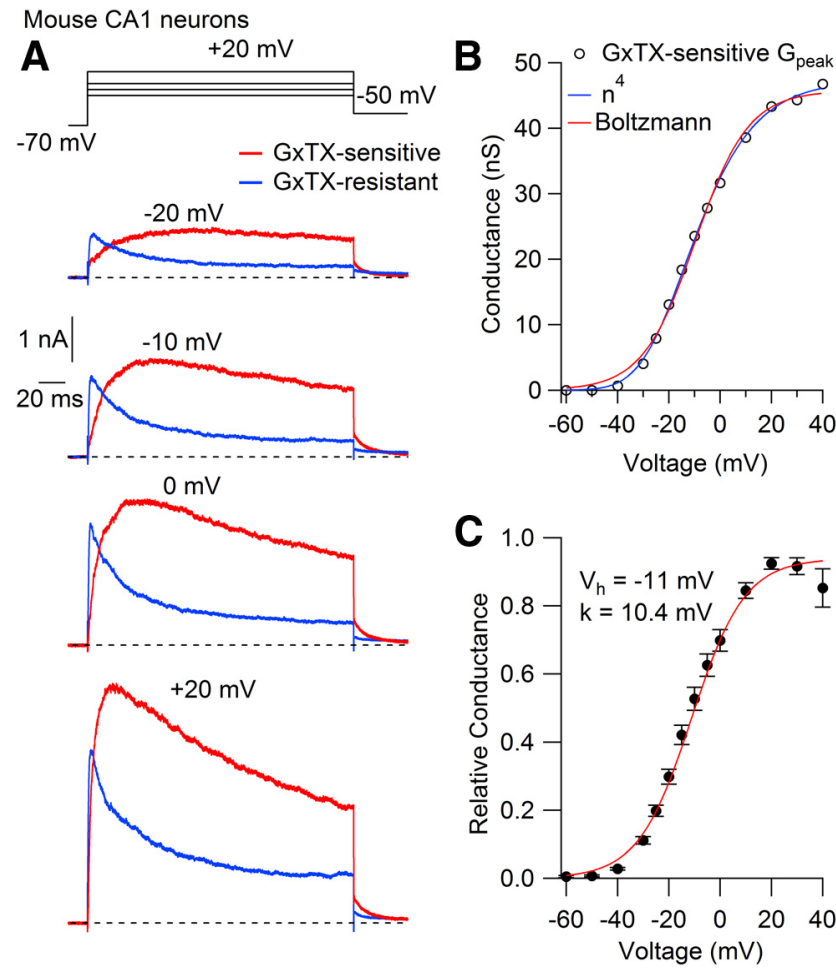

Figure 7. Voltage dependence of Kv2 current determined by GxTX subtraction in mouse CA1 pyramidal neurons. $\boldsymbol{A}$, GxTX-sensitive (red) and GXTX-resistant (blue) current determined by application of $100 \mathrm{~nm}$ GXTX-1E. Solution contained $1 \mu \mathrm{m}$ TTX. $\boldsymbol{B}$, Voltage dependence of activation of peak GxTX-sensitive conductance from the cell in $\boldsymbol{A}$. Peak conductance was calculated from peak current using a reversal potential of $-99 \mathrm{mV}$, the calculated potassium equilibrium potential with the solutions used. Solid red line, Fit to simple Boltzmann function $1 /(1+\exp -$ $\left.\left(V-V_{\mathrm{h}}\right) / k\right)$, where $V_{\mathrm{h}}=-10.1 \mathrm{mV}$ is the midpoint and $k=10.7 \mathrm{mV}$ is the slope factor. Solid blue line, Fit to a Boltzmann function raised to fourth power, $\left[1 /\left(1+\exp -\left(V-V_{h n}\right) / k_{n}\right)\right]^{4}$, where $V_{\mathrm{hn}}=-34.9 \mathrm{mV}$ is the voltage at which half of the $n$ particles are in the activated position and $k_{\mathrm{n}}=15.1 \mathrm{mV}$ is the slope factor for activation of $n$ particles. $C$, Mean \pm SEM for normalized conductance in 20 CA1 neurons. Solid red line, Boltzmann function $1 /(1+\exp -$ $\left.\left(V-V_{\mathrm{h}}\right) / k\right)$, where $V_{\mathrm{h}}=-11.2 \mathrm{mV}$ and $k=10.4 \mathrm{mV}$ are mean values of results of separate fits in each cell (SEM values of 1.3 and $0.5 \mathrm{mV}$, respectively). Average maximal conductance was $48 \pm 7 \mathrm{nS}(n=20)$.

rent, the GxTX-sensitive current activated relatively slowly, whereas the GxTX-resistant current activated much more rapidly (Fig. 7A). In collected results for a step from $-70 \mathrm{mV}$ to $-10 \mathrm{mV}$, the time to half-maximal GxTX-sensitive current was $4.6 \pm 0.4$ ms compared with $1.7 \pm 0.2 \mathrm{~ms}$ for the GxTX-resistant current $\left(n=22, p=1.2 \times 10^{-6}\right)$. In addition, the current remaining in GxTX-1E inactivated faster and more completely during $200 \mathrm{~ms}$ test pulses than the GxTX-sensitive current (Fig. 7A). We believe the GxTX-resistant current likely contains multiple components, because the speed and degree of inactivation varied considerably from cell to cell. Based on previous analysis of potassium currents in hippocampal and cortical pyramidal neurons, the GxTXresistant current includes components from Kv4 and Kv1 family subunits (Kim et al., 2005; Chen et al., 2006; Guan et al., 2007a, 2007b, 2011; Carrasquillo et al., 2012; Kim and Hoffman, 2012). We found that some of the GxTX-resistant current could be blocked by $1 \mathrm{~mm}$ TEA, but this block was not selective because $1 \mathrm{~mm}$ TEA also clearly partially inhibited the slowly-activating slowly-deactivating GxTX-sensitive component of current. This is consistent with a previous demonstration that the Kv2-mediated current in cortical pyramidal neurons is sensitive to low millimolar concentrations of TEA (Guan et al., 2007). 


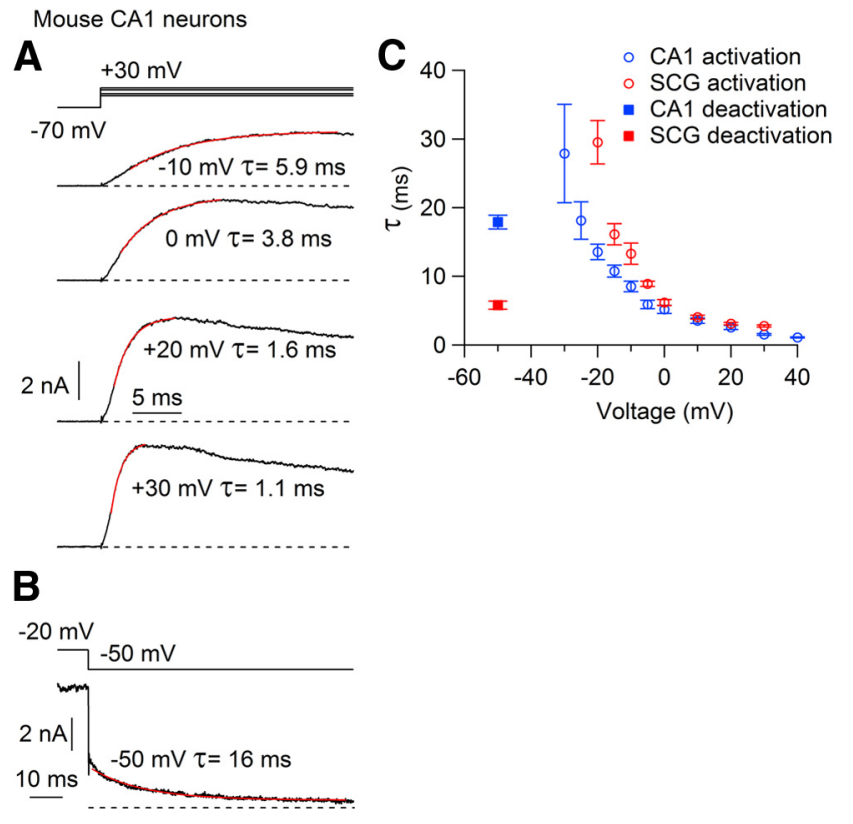

Figure 8. Activation and deactivation kinetics of Kv2 current in mouse CA1 pyramidal neurons. A, Activation kinetics of Kv2 current isolated by GxTX subtraction with $100 \mathrm{~nm}$ GXTX-1E. Red lines, Single exponential fit to rising phase of current fit from $35 \%$ to maximal current. $\boldsymbol{B}$, Kinetics of deactivation at $-50 \mathrm{mV}$. Red line, Fit to a single exponential. C, Time constants from single exponential fits as a function of voltage. Mean \pm SEM for determinations in 20 CA1 neurons (blue symbols) compared with measurements made in the same way in seven SCG neurons (red symbols). Activation was fit starting at 35\% of the rise (to avoid the lag) and deactivation was fit to the final $80 \%$ of the decay.

Although the current remaining in GxTX-1E appeared heterogenous and varied in its kinetics from cell to cell, the GxTX-sensitive component was highly consistent in its voltage dependence and kinetics from cell to cell. Figure $7 B$ shows a typical activation curve of GxTX-sensitive current in a CA1 pyramidal neuron, activating with a midpoint near $-10 \mathrm{mV}$. As for the GxTX-sensitive current in SCG neurons, the fit was better with a Boltzmann function raised to the fourth power than with a simple Boltzmann function. In collected results for fits to an $n^{4}$ scheme, $V_{\mathrm{hn}}$ was $-35.3 \pm 0.8 \mathrm{mV}$ and $k_{\mathrm{n}}$ was $16.5 \pm 0.9 \mathrm{mV}(n=$ $20)$. Figure $7 C$ shows an activation curve constructed from averaged data in 20 CA1 pyramidal cells. The voltage dependence of the collected data was described fairly well by a simple Boltzmann curve constructed from the averaged midpoints and slope factors of the individual cells, with a midpoint of $-11.2 \pm 1.3 \mathrm{mV}$ and slope factor of $10.4 \pm 0.5 \mathrm{mV}(n=20)$. This voltage dependence is generally similar to that of Kv2 current in neocortical pyramidal neurons defined by stromatoxin block (midpoint $-3 \mathrm{mV}$, slope factor $10.5 \mathrm{mV}$; Guan et al., 2007) and a component of current in globus pallidus neurons with slow deactivation proposed to be Kv2 mediated (midpoint $-18 \mathrm{mV}$, slope factor $7 \mathrm{mV}$; Baranauskas et al., 1999).

Figure 8 shows the kinetics of the GxTX-sensitive current in CA1 pyramidal neurons. We did not describe the time course of activation with $n^{4}$ kinetics because the fits were generally imperfect even if confined to the initial rising phase. However, the main part of the rising phase could be fit quite well with a single exponential function. Figure $8 \mathrm{~A}$ shows fits to the rising phase starting at $35 \%$, avoiding the initial lag. This dominant time constant of activation was strongly voltage dependent, decreasing from $8.5 \pm$ $0.8 \mathrm{~ms}$ at $-10 \mathrm{mV}$ to $1.5 \pm 0.1 \mathrm{~ms}$ at $+30 \mathrm{mV}(n=20)$. The dominant time constant of activation was somewhat faster in
CA1 neurons than in SCG neurons (at $-10 \mathrm{mV}, 8.5 \pm 0.8 \mathrm{~ms}$ in CA1 vs $13.3 \pm 1.5 \mathrm{~ms}$ in SCG neurons and at $+30 \mathrm{mV}, 1.5 \pm 0.1$ $\mathrm{ms}$ in CA1 vs $2.8 \pm 0.2 \mathrm{~ms}$ in SCG neurons; $n=20$ for CA 1 and $n=7$ for SCG). Interestingly, however, the time constant of deactivation was substantially longer in CA1 pyramidal neurons than in SCG neurons (at $-50 \mathrm{mV}, 17.9 \pm 1.1 \mathrm{~ms}$ in CA1 vs $5.8 \pm$ $0.6 \mathrm{~ms}$ in SCG; $n=20$ for CA1 and $n=7$ for SCG).

\section{Effect of GxTX-1E on action potential shape in hippocampal CA1 neurons}

We next tested the effects of GxTX-1E on action potentials and firing behavior in current-clamp recordings from hippocampal CA1 neurons. An initial observation was that whether or not GxTX-1E broadened the action potential depended on the membrane potential from which the action potential was elicited. Figure 9 shows the effect of GxTX-1E on action potentials evoked from $-80 \mathrm{mV}$ (left) or $-70 \mathrm{mV}$ (right). In either case, GxTX-1E had no effect on the action potential threshold or on the rising phase of the action potential, as expected from the slow kinetics of activation of Kv2 current. For action potentials evoked from -80 $\mathrm{mV}$, there was no effect on the initial phase of repolarization, but the late phase of repolarization was slowed and the trough voltage reached after the spike was substantially less negative in the presence of GxTX-1E (Fig. 9A). In collected results for action potentials evoked from near $-80 \mathrm{mV}$, the width of the action potential measured at half-maximum was not significantly altered by GxTX-1E (control, $0.83 \pm 0.04 \mathrm{~ms}$; GxTX-1E, $0.89 \pm 0.04 \mathrm{~ms}$, $n=7 ; p=0.12$ ), but the trough after the action potential depolarized by $8.6 \pm 1.9 \mathrm{mV}$, from $-74.9 \pm 1.7 \mathrm{mV}$ in control to $-66.3 \pm 2.1 \mathrm{mV}$ in $100 \mathrm{~nm} \mathrm{GxTX}-1 \mathrm{E}(n=7 ; p=0.005)$. These results suggest that from holding potentials near $-80 \mathrm{mV}$, potassium currents other than Kv2 produce the initial repolarization before Kv2 currents are able to activate. However, Kv2 channels clearly activated significantly in the late phases of repolarization, because blocking them does strongly affect the trough voltage immediately after the spike.

The resting potential of CA1 pyramidal neurons can vary between approximately -65 to $-85 \mathrm{mV}$ (Spruston and Johnston, 1992; Fricker et al., 1999; Staff et al., 2000; Kaczorowski et al., 2007). When action potentials were evoked from near $-70 \mathrm{mV}$ rather than $-80 \mathrm{mV}$, blocking Kv2 channels with GxTX-1E had no effect on approach to threshold or the rising phase of the action potential, but did produce a slowing of repolarization even in the early phases so that the width of action potential at halfmaximum amplitude was significantly increased by GxTX-1E (Fig. 9B). In collected results for action potentials elicited from near $-70 \mathrm{mV}$, the width of the spike increased from $1.02 \pm 0.06$ $\mathrm{ms}$ in control to $1.30 \pm 0.08 \mathrm{~ms}$ in $100 \mathrm{nM} \mathrm{GxTX}-1 \mathrm{E}(n=7, p=$ 0.005 ; Fig. 9 C). Therefore, there is a more prominent role of $\mathrm{Kv} 2$ channels during early spike repolarization when spikes are evoked from $-70 \mathrm{mV}$ than from $-80 \mathrm{mV}$. A possible explanation is that potassium current from other types of potassium channels is more prominent for early repolarization for spikes evoked from $-80 \mathrm{mV}$ compared with $-70 \mathrm{mV}$ as a consequence of partial steady-state inactivation at $-70 \mathrm{mV}$. Such inactivation of potassium currents is consistent with the substantially broader spikes evoked from $-70 \mathrm{mV}(1.02 \pm 0.06 \mathrm{~ms})$ compared with spikes evoked from $-80 \mathrm{mV}(0.83 \pm 0.04 \mathrm{~ms}, n=7 ; p=0.04)$ This effect is consistent with previous evidence for a major role of $I_{\mathrm{A}}$ in repolarization of action potentials in CA1 pyramidal neurons (Kim et al., 2005; Andrásfalvy et al., 2008) and it is also possible that steady-state inactivation of other channel types such as Kv1 family (D-type) or Kv3 family channels could be involved. 

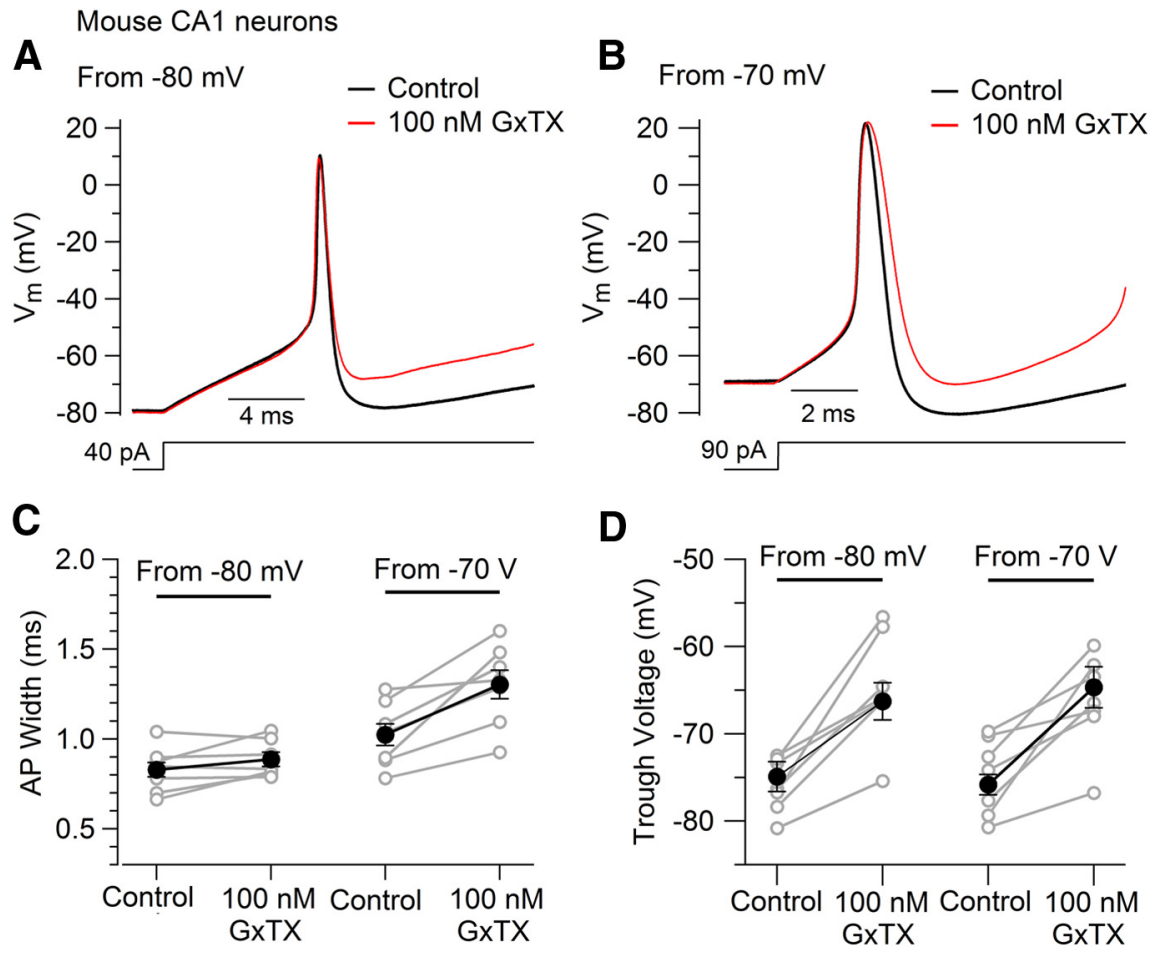

Figure 9. Effect of GXTX-1E on action potentials in mouse hippocampal CA1 neurons. $\boldsymbol{A}$, Effect of $100 \mathrm{~nm}$ GXTX-1E on action potentials evoked by a $40 \mathrm{pA}$ current injection from a membrane potential near $-80 \mathrm{mV}$. $\boldsymbol{B}$, Effect of $100 \mathrm{~nm}$ GxTX-1E on action potentials evoked by a $90 \mathrm{pA}$ current injection from a membrane potential near $-70 \mathrm{mV}$. The action potential with $100 \mathrm{~nm}$ GXTX-1E activated slightly earlier due to a slightly $(\sim 1 \mathrm{mV})$ more depolarized membrane potential; to better compare the shapes, it has

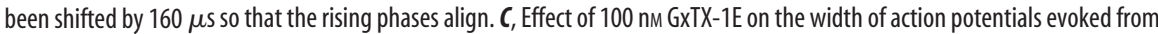
near $-80 \mathrm{mV}$ or $-70 \mathrm{mV}$. Width was measured at half-amplitude of the action potential measured from the depolarizing phase. Measurements were made for action potentials evoked by a current injection of $50 \mathrm{pA}$. Connected gray circles show changes in individual cells; connected black circles show mean values. For $-80 \mathrm{mV}$ data, control mean was $0.83 \pm 0.04$ ms and GxTX mean was $0.89 \pm 0.04 \mathrm{~ms}, n=7 ; p=0.12$. Average $V_{\mathrm{m}}$ before current injection was $-79.5 \pm 0.8 \mathrm{mV}$. For $-70 \mathrm{mV}$ data, control mean was $1.02 \pm 0.06 \mathrm{~ms}$ and $\mathrm{GXTX}$ mean was $1.30 \pm 0.08 \mathrm{~ms} ; n=7, p=0.005$. Average $V_{\mathrm{m}}$ before current injection was $-68.2 \pm$

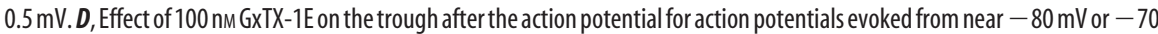
$\mathrm{mV}$ (same action potentials as in C). Trough was measured at the most negative voltage after the spike. Measurements were made for action potentials evoked by a current injection of $50 \mathrm{pA}$. Connected gray circles show changes in individual cells; connected black circles show mean values. For $-80 \mathrm{mV}$ data, control mean was $-74.9 \pm 1.7 \mathrm{mV}$ and GxTX mean was $-66.3 \pm 2.1 \mathrm{mV}, n=7$; $p=0.005$. For $-70 \mathrm{mV}$ data, control mean was $-75.8 \pm 1.2 \mathrm{mV}$ and $\mathrm{GxTX}$ mean was $-64.7 \pm 2.4 \mathrm{mV} ; n=7, p=0.001$.

These results show that the relative role of Kv2 channels in early action potential repolarization in CA1 pyramidal neurons depends on resting potential, with a significant role in early repolarization for action potentials elicited from $-70 \mathrm{mV}$. However, even for the narrower action potentials evoked from near $-80 \mathrm{mV}$, blocking Kv2 channels with GxTX-1E caused dramatic slowing of the late phase of repolarization and a more depolarized trough voltage after the spike. Therefore, even in this case, Kv2 channels are activated during the action potential, although activation is not substantial until the late phase of repolarization.

\section{GxTX-1E increases initial firing frequency but inhibits maintained firing in hippocampal CA1 neurons}

As in SCG neurons, the effects of blocking Kv2 channels with GxTX-1E in CA1 pyramidal neurons were most dramatic during repetitive firing evoked by maintained current pulses; an example is shown in Figure 10A. GxTX-1E had little effect on the rising phase or peak of the first action potential. However, there was a dramatic effect on subsequent firing. In control, steady firing was maintained throughout the $500 \mathrm{~ms}$ period with little change in action potential peaks and troughs. However, in the presence of GxTX-1E, there was a progressive reduction of spike height ac- companied by increasingly depolarized trough voltages. By the end of the $500 \mathrm{~ms}$ period of current injection, firing of spikes had ceased completely and there were only small oscillations of membrane potential around an average voltage of approximately $-45 \mathrm{mV}$. Therefore, the ability to fire in a maintained manner is greatly diminished with loss of $\mathrm{Kv} 2$ current.

The changes in firing behavior induced by GxTX-1E in hippocampal CA1 pyramidal neurons during long current pulses are illustrated in Figure 10, $B-E$, plotted as a function of stimulating current. The initial firing rate was faster after blocking Kv2 channels. This effect was larger for larger current injections, so that there was an increase in the slope of the frequencycurrent curve after blocking Kv2 channels (Fig. 10B). For the neuron shown in Figure 10 , the initial firing frequency under control conditions reached a maximum of $105 \mathrm{~Hz}$, which was achieved with a $180 \mathrm{pA}$ current injection. After blocking Kv2 channels, the maximal frequency was higher $(136 \mathrm{~Hz})$ and was achieved by a much smaller current injection (90 pA). The increased initial firing frequency with GxTX-1E was seen in all cells. In collected results, the initial firing rate for a $40 \mathrm{pA}$ current injection increased from $46 \pm 3$ $\mathrm{Hz}$ in control to $67 \pm 6 \mathrm{~Hz}$ in $100 \mathrm{nM}$ GxTX-1E $(n=6, p=0.003)$.

The firing frequency averaged over the entire $500 \mathrm{~ms}$ period of current injection also increased after blocking Kv2 channels (Fig. 10C), but less dramatically and only for small and moderate current injections, up to $\sim 40-50 \mathrm{pA}$. For larger current injections, the number of spikes during the 500 ms current injection dropped sharply after blocking Kv2 channels as a result of the fade-out of firing later in the pulse, as illustrated in Figure 10A.

The inability to maintain firing with large current injections after block of Kv2 channels was associated with progressive depolarization of the membrane voltage between spikes beginning with the voltage after the first spike (Fig. 10D). The trough after the first spike changed from $-76 \pm 2$ in control to $-68 \pm 2 \mathrm{mV}$ in GxTX-1E (for a $40 \mathrm{pA}$ current injection, $n=7 ; \mathrm{p}=0.009$ ). As a consequence of the depolarization of the interspike voltage, block of Kv2 channels also resulted in depolarization of the average membrane potential during the entire $500 \mathrm{~ms}$ current injection (Fig. 10E). In collected results, the average membrane voltage during a $40 \mathrm{pA}$ current injection depolarized from $-64 \pm$ $1 \mathrm{mV}$ in control to $-56 \pm 2 \mathrm{mV}$ in GxTX-1E $(n=7, p=0.003)$. The depolarization of average membrane potential was correlated with the inability to maintain firing. As can be seen by comparing Figure 10, $C$ and $E$, both in control and after blocking Kv2 channels, firing failed when an average membrane potential of approximately $-45 \mathrm{mV}$ was reached. This occurred for much smaller current injections after blocking Kv2 channels. 

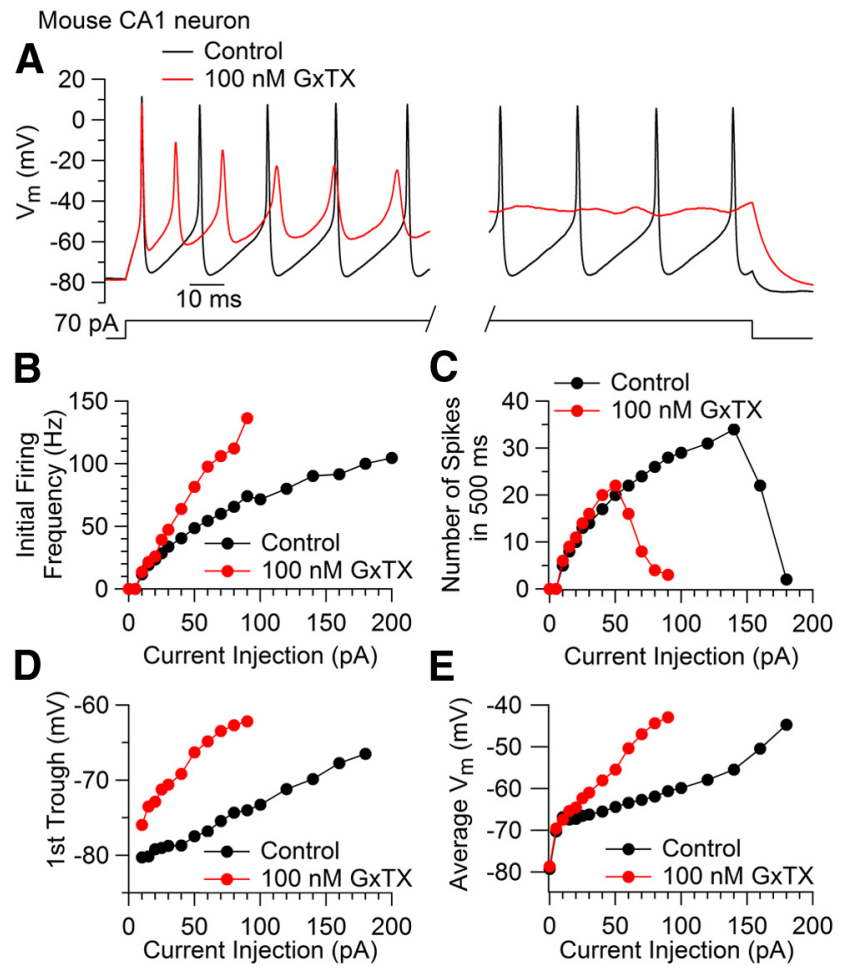

Figure 10. Effect of GxTX-1E on repetitive firing in a mouse hippocampal CA1 neuron. $\boldsymbol{A}$, Effect of $100 \mathrm{~nm}$ GXTX-1E on repetitive firing elicited by a $70 \mathrm{pA}$ current injection for $500 \mathrm{~ms}$. $\boldsymbol{B}$, Initial firing frequency (calculated from first two spikes) as a function of injected current. $\boldsymbol{C}$, Number of spikes in the $500 \mathrm{~ms}$ current injection period (with a height criterion of $40 \mathrm{mV}$ ). D, Most negative voltage (trough) between first and second spikes. $\boldsymbol{E}$, Average membrane potential during the current injection.

With Kv2 channels blocked by GxTX-1E, the association of the fade-out of firing during a maintained current injection with progressive depolarization of the interspike voltages suggests that the loss of firing reflects progressive inactivation of sodium channels as a result of the progressive depolarization between spikes, similar to the results in SCG neurons. Kv2 channels thus appear to be critical for producing sufficiently negative afterhyperpolarizations to allow recovery of sodium channels and to prevent depolarization block.

\section{Discussion}

\section{Efficacy and selectivity of GxTX-1E}

Our results suggest that GxTX-1E can be used as an effective and reasonably selective inhibitor of Kv2 channels in mammalian neurons. The initial characterization of GxTX-1E showed inhibition of cloned Kv2.1 and Kv2.2 channels with an $\mathrm{IC}_{50}$ of $2-5 \mathrm{nM}$, with somewhat weaker effects on native delayed-rectifier current in pancreatic $\beta$ cells (Herrington et al., 2006). Our results show comparable sensitivity of native Kv2 currents in hippocampal neurons and SCG sympathetic neurons, with near-saturating effects of 100 nM GXTX-1E on delayed rectifier current in both cell types.

GxTX-1E was previously found to have no effect on cloned Kv1.2, Kv1.3, Kv1.5, Kv3.2, or BK calcium-activated channels or any of several types of cloned voltage-dependent sodium and calcium channels tested (Herrington et al., 2006). Our results showed a small effect on the native sodium current in SCG neurons (7\% inhibition at $100 \mathrm{~nm}$ GxTX-1E) and no effect on calcium current.

GxTX-1E also has blocking activity against Kv4 family channels (Herrington et al., 2006), which generate $I_{\mathrm{A}}$ in the cell bodies and dendrites of mammalian neurons, including SCG and CA1 pyramidal neurons (Malin and Nerbonne, 2001; Kim et al., 2005, 2007; Whyment et al., 2011). GxTX-1E inhibits heterologously expressed $\mathrm{Kv} 4.3$ channels with an $\mathrm{IC}_{50}$ of 24-54 nM (Herrington et al., 2006). Interestingly, inhibition of native $I_{\mathrm{A}}$ in SCG neurons was considerably weaker ( $8 \%$ by $100 \mathrm{~nm}$ GxTX-1E and $19 \%$ by $200 \mathrm{~nm}$ GxTX-1E). This may reflect weaker block of Kv4.2 or K4.1 compared with $\mathrm{Kv} 4.3$ or the influence of accessory subunits. These results suggest $100 \mathrm{~nm}$ GxTX-1E as an optimal concentration to use in current-clamp experiments, with nearly saturating effects on Kv2 but minimal effects on $I_{\mathrm{A}}$.

Although it is difficult to rule out small effects of GxTX-1E on other native channels in addition to Kv2, the totality of evidence suggests that any such effects must be small. First, the GxTXsensitive current had well defined characteristics expected of Kv2 channels, including slow activation and slow deactivation. Second, the component of current blocked by GxTX-1E showed saturation between 100 and $200 \mathrm{~nm}$ toxin. Third, the voltage dependence and kinetics of the GxTX-sensitive current were highly uniform among the cells of each type and were dramatically different from the GxTX-1E-resistant current, which was much more variable from cell to cell. Finally, a high degree of selectivity is suggested by the lack of effect of GxTX-1E on the threshold of action potentials or on the initial falling phase (up to the midpoint) in CA1 neuron action potentials evoked from $-80 \mathrm{mV}$.

GxTX-1E has clear advantages compared with stromatoxin, the blocker previously used to study Kv2 in neurons (Guan et al., 2007), including higher potency for Kv2 block and much weaker block of $\mathrm{Kv} 4$ (blocked by stromatoxin with an $\mathrm{IC}_{50}$ of $\sim 1 \mathrm{nM}$; Escoubas et al., 2002). Both toxins inhibit Kv2 channels by shifting activation to more depolarized voltages (Escoubas et al., 2002; Herrington et al., 2006), but, whereas stromatoxin inhibition can be relieved in a time-dependent manner during depolarizations positive to $+10 \mathrm{mV}$ (Escoubas et al., 2002), making it difficult to perform accurate subtractions to define Kv2 current, we saw no such relief of GxTX-1E inhibition during $200 \mathrm{~ms}$ depolarizations to voltages up to $+40 \mathrm{mV}$ (though relief was evident positive to $+50 \mathrm{mV})$.

\section{Influence of $\mathrm{Kv} \mathbf{2}$ channels on excitability}

Understanding how Kv2 channels influence excitability is of particular interest because of accumulating evidence that Kv2mediated current in central neurons is unusually dynamic. Kv2 channels are subject to a remarkable range of modulatory influences that can alter functional expression (Misonou et al., 2004; O'Connell et al., 2010; Fox et al., 2013) through regulation by phosporylation (Murakoshi et al., 1997; Mohapatra et al., 2007; Cerda and Trimmer, 2011; Ikematsu et al., 2011), sumoylation (Plant et al., 2011), and nitric oxide-associated pathways (Steinert et al., 2011). This modulation can mediate plasticity of neuronal firing (Mohapatra et al., 2009; Nataraj et al., 2010; Steinert et al., 2011), although, in general, it is difficult to be certain that changes in firing from modulatory influences are exclusively due to changes in Kv2.

At least in cultured neurons, many Kv2 channels appear to be nonconducting (Fox et al., 2013), possibly playing nonelectrical roles in vesicle trafficking or facilitating membrane expression of other membrane proteins (Deutsch et al., 2012). Nevertheless, in combination with previous results (Du et al., 2000; Malin and Nerbonne, 2002; Johnston et al., 2008; Guan et al., 2013; Tong et al., 2013), our experiments show that the purely electrical function of Kv2 channels in central neurons is very substantial, influ- 
encing action potential width and strongly regulating repetitive firing.

In SCG neurons, the action potential clamp experiments showed that Kv2 channels activate significantly soon after the peak of the action potential and carry approximately half of the total outward current during repolarization. Accordingly, GxTX-1E produced substantial broadening of SCG action potentials. These results at $37^{\circ} \mathrm{C}$ buttress previous evidence showing broadening of SCG action potentials at room temperature with Kv2 reduction by a dominant-negative strategy (Malin and Nerbonne, 2002).

In CA1 pyramidal neurons, GxTX-1E produced significant broadening of action potentials (at half-amplitude) when spikes were elicited from $-70 \mathrm{mV}$, but not of the narrower spikes evoked from $-80 \mathrm{mV}$. However, even for spikes evoked from $-80 \mathrm{mV}$, inhibiting $\mathrm{Kv} 2$ resulted in a substantial $(\sim 8 \mathrm{mV})$ depolarization of the trough voltage after a spike, similar to the average $\sim 9 \mathrm{mV}$ depolarization of the trough voltage in SCG neurons. Therefore, Kv2 channels are clearly activated by the time spike repolarization is complete in both cases. The powerful contribution of Kv2 conductance to the trough voltage likely reflects its slow deactivation kinetics. In CA1 neurons, it is striking that Kv2 channels play a major role in regulating trough voltages even in conditions when they contribute negligibly to early repolarization.

These results show that even though Kv2 channels activate relatively slowly, they can still be activated during single action potentials and can help to control spike width in CA1 pyramidal neurons for spikes evoked from near $-70 \mathrm{mV}$ (with halfmaximal width $\sim 1 \mathrm{~ms}$ at $37^{\circ} \mathrm{C}$ ). Even though only a small fraction of Kv2 channels are likely to be activated at the time of half-repolarization, the very large amplitude of maximal Kv2 current means this partial activation can be significant. An even more striking example of the importance of Kv2 channels for spike repolarization was reported for auditory neurons in the ventral and medial nuclei of the trapezoid body, in which loss of Kv2.2 channels resulted in substantial spike broadening even for much narrower (0.3-0.5 ms) spikes (Tong et al., 2013).

\section{Variable effects of Kv2 on initial firing frequency}

The complex effects of inhibiting Kv2 current on firing frequency reveals the impossibility of making a simple statement about how upregulating or downregulating the expression of Kv2 channels will alter neuronal excitability. In CA1 neurons, inhibition of Kv2 channels resulted in an enhancement of initial firing frequency for moderate levels of stimulation, as intuitively expected from inhibition of voltage-dependent potassium current. However, the enhancement of initial firing frequency was minimal in sympathetic neurons, apparently because the depolarization of the trough after the first spike reduced the fraction of sodium channels able to recover from inactivation, tending to slow firing of the second spike. What effect a more depolarized trough has on subsequent action potentials likely depends on the details of the sodium channels in the neuron, including voltage dependence of inactivation, kinetics of recovery from inactivation, and what fraction of sodium channels is needed to generate an action potential with a rapid rising phase. CA1 pyramidal neurons have an "excess" of sodium channels in the sense that inhibition of a substantial fraction of sodium channels by TTX has almost no effect on action potential generation (Madeja, 2000). Therefore, reduced recovery from inactivation of sodium channels may have relatively little effect until the loss of available sodium channels is severe.
The most dramatic effect of Kv2 channel inhibition was early failure of repetitive firing for moderate and strong current injections, which was seen in both cell types. Our results using GxTX-1E block adds to previous results using knock-out, antisense, and dominant-negative strategies to suggest an importance of $\mathrm{Kv} 2$ channels for enabling repetitive firing that extends over a wide range of neuronal types (Du et al., 2000; Malin and Nerbonne, 2002; Guan et al., 2013; Tong et al., 2013). Our data also fit well with previous proposals (Johnston et al., 2010; Guan et al., 2013; Tong et al., 2013) that the key factor of Kv2 activation to enable repetitive firing is to promote strong afterhyperpolarization as a consequence of slow deactivation. We find that this effect of Kv2 activation is prominent even after the first action potential in a train and is maintained during firing over half a second. A strong hyperpolarization from Kv2 channels is apparently critical to permit sufficient recovery from inactivation of sodium channels to generate subsequent action potentials and, in its absence, many types of neurons are unable to maintain repetitive firing in a normal manner.

\section{References}

Andrásfalvy BK, Makara JK, Johnston D, Magee JC (2008) Altered synaptic and non-synaptic properties of CA1 pyramidal neurons in Kv4.2 knockout mice. J Physiol 586:3881-3892. CrossRef Medline

Baranauskas G, Tkatch T, Surmeier DJ (1999) Delayed rectifier currents in rat globus pallidus neurons are attributable to Kv2.1 and Kv3.1/3.2 K(+) channels. J Neurosci 19:6394-6404. Medline

Blair NT, Bean BP (2002) Roles of tetrodotoxin (TTX)-sensitive $\mathrm{Na}^{+}$current, TTX-resistant $\mathrm{Na}^{+}$current, and $\mathrm{Ca}^{2+}$ current in the action potentials of nociceptive sensory neurons. J Neurosci 22:10277-10290. Medline

Carrasquillo Y, Burkhalter A, Nerbonne JM (2012) A-type K+ channels encoded by Kv4.2, Kv4.3 and Kv1.4 differentially regulate intrinsic excitability of cortical pyramidal neurons. J Physiol 590:3877-3890. CrossRef Medline

Carter BC, Bean BP (2009) Sodium entry during action potentials of mammalian neurons: incomplete inactivation and reduced metabolic efficiency in fast-spiking neurons. Neuron 64:898-909. CrossRef Medline

Cerda O, Trimmer JS (2011) Activity-dependent phosphorylation of neuronal Kv2.1 potassium channels by CDK5. J Biol Chem 286:28738-28748. CrossRef Medline

Chen X, Yuan LL, Zhao C, Birnbaum SG, Frick A, Jung WE, Schwarz TL, Sweatt JD, Johnston D (2006) Deletion of Kv4.2 gene eliminates dendritic A-type $\mathrm{K}+$ current and enhances induction of long-term potentiation in hippocampal CA1 pyramidal neurons. J Neurosci 26:1214312151. CrossRef Medline

de Haas V, Vogel W (1989) Sodium and potassium currents recorded during an action potential. Eur Biophys J 17:49-51. Medline

Deutsch E, Weigel AV, Akin EJ, Fox P, Hansen G, Haberkorn CJ, Loftus R, Krapf D, Tamkun MM (2012) Kv2.1 cell surface clusters are insertion platforms for ion channel delivery to the plasma membrane. Mol Biol Cell 23:2917-2929. CrossRef Medline

Du J, Tao-Cheng JH, Zerfas P, McBain CJ (1998) The $\mathrm{K}^{+}$channel, Kv2.1, is apposed to astrocytic processes and is associated with inhibitory postsynaptic membranes in hippocampal and cortical principal neurons and inhibitory interneurons. Neuroscience 84:37-48. CrossRef Medline

Du J, Haak LL, Phillips-Tansey E, Russell JT, McBain CJ (2000) Frequencydependent regulation of rat hippocampal somato-dendritic excitability by the $\mathrm{K}^{+}$channel subunit Kv2.1. J Physiol 522:19-31. CrossRef Medline

Escoubas P, Diochot S, Célérier ML, Nakajima T, Lazdunski M (2002) Novel tarantula toxins for subtypes of voltage-dependent potassium channels in the Kv2 and Kv4 subfamilies. Mol Pharmacol 62:48-57. CrossRef Medline

Fox PD, Loftus RJ, Tamkun MM (2013) Regulation of Kv2.1 K(+) conductance by cell surface channel density. J Neurosci 33:1259-1270. CrossRef Medline

Fricker D, Verheugen JA, Miles R (1999) Cell-attached measurements of the firing threshold of rat hippocampal neurones. J Physiol 517:791-804. CrossRef Medline

Guan D, Lee JC, Higgs MH, Spain WJ, Foehring RC (2007) Functional roles 
of Kv1 channels in neocortical pyramidal neurons. J Neurophysiol 97: 1931-1940. CrossRef Medline

Guan D, Tkatch T, Surmeier DJ, Armstrong WE, Foehring RC (2007) Kv2 subunits underlie slowly inactivating potassium current in rat neocortical pyramidal neurons. J Physiol 581:941-960. CrossRef Medline

Guan D, Horton LR, Armstrong WE, Foehring RC (2011) Postnatal development of A-type and Kv1- and Kv2-mediated potassium channel currents in neocortical pyramidal neurons. J Neurophysiol 105:2976-2988. CrossRef Medline

Guan D, Armstrong WE, Foehring RC (2013) Kv2 channels regulate firing rate in pyramidal neurons from rat sensorimotor cortex. J Physiol (England) 591:4807-4825. CrossRef

Herrington J (2007) Gating modifier peptides as probes of pancreatic betacell physiology. Toxicon 49:231-238. CrossRef Medline

Herrington J, Zhou YP, Bugianesi RM, Dulski PM, Feng Y, Warren VA, Smith MM, Kohler MG, Garsky VM, Sanchez M, Wagner M, Raphaelli K, Banerjee P, Ahaghotu C, Wunderler D, Priest BT, Mehl JT, Garcia ML, McManus OB, Kaczorowski GJ, Slaughter RS (2006) Blockers of the delayed-rectifier potassium current in pancreatic beta-cells enhance glucose-dependent insulin secretion. Diabetes 55:1034-1042. CrossRef Medline

Hille B (2001) Ion channels of excitable membranes, Ed 3. Sunderland, MA: Sinauer.

Hodgkin AL, Huxley AF (1952) A quantitative description of membrane current and its application to conduction and excitation in nerve. J Physiol 117:500-544. Medline

Hwang PM, Fotuhi M, Bredt DS, Cunningham AM, Snyder SH (1993) Contrasting immunohistochemical localizations in rat brain of two novel $\mathrm{K}^{+}$ channels of the Shab subfamily. J Neurosci 13:1569-1576. Medline

Ikematsu N, Dallas ML, Ross FA, Lewis RW, Rafferty JN, David JA, Suman R, Peers C, Hardie DG, Evans AM (2011) Phosphorylation of the voltagegated potassium channel Kv2.1 by AMP-activated protein kinase regulates membrane excitability. Proc Natl Acad Sci U S A 108:18132-18137. CrossRef Medline

Johnston J, Griffin SJ, Baker C, Skrzypiec A, Chernova T, Forsythe ID (2008) Initial segment Kv2.2 channels mediate a slow delayed rectifier and maintain high frequency action potential firing in medial nucleus of the trapezoid body neurons. J Physiol 586:3493-3509. CrossRef Medline

Johnston J, Forsythe ID, Kopp-Scheinpflug C (2010) Going native: voltagegated potassium channels controlling neuronal excitability. J Physiol 588: 3187-3200. CrossRef Medline

Kaczorowski CC, Disterhoft J, Spruston N (2007) Stability and plasticity of intrinsic membrane properties in hippocampal CA1 pyramidal neurons: effects of internal anions. J Physiol 578:799-818. CrossRef Medline

Kim E, Hoffman DA (2012) Dynamic regulation of synaptic maturation state by voltage-gated A-type $\mathrm{K}+$ channels in CA1 hippocampal pyramidal neurons. J Neurosci 32:14427-14432. CrossRef Medline

Kim J, Wei DS, Hoffman DA (2005) Kv4 potassium channel subunits control action potential repolarization and frequency-dependent broadening in rat hippocampal CA1 pyramidal neurones. J Physiol 569:41-57. CrossRef Medline

Kim J, Jung SC, Clemens AM, Petralia RS, Hoffman DA (2007) Regulation of dendritic excitability by activity-dependent trafficking of the A-type K+ channel subunit Kv4.2 in hippocampal neurons. Neuron 54:933-947. CrossRef Medline

Liu P, Jo S, Bean BP (2012) Modulation of neuronal sodium channels by the sea anemone peptide BDS-I. J Neurophysiol 107:3155-3167. CrossRef Medline

Madeja M (2000) Do neurons have a reserve of sodium channels for the generation of action potentials? A study on acutely isolated CA1 neurons from the guinea-pig hippocampus. Eur J Neurosci 12:1-7. CrossRef Medline

Malin SA, Nerbonne JM (2001) Molecular heterogeneity of the voltagegated fast transient outward $\mathrm{K}+$ current, I(Af), in mammalian neurons. J Neurosci 21:8004-8014. Medline

Malin SA, Nerbonne JM (2002) Delayed rectifier $\mathrm{K}^{+}$currents, IK, are encoded by Kv2 alpha-subunits and regulate tonic firing in mammalian sympathetic neurons. J Neurosci 22:10094-10105. Medline

Misonou H, Mohapatra DP, Park EW, Leung V, Zhen D, Misonou K, Anderson AE, TrimmerJS (2004) Regulation of ion channel localization and phosphorylation by neuronal activity. Nat Neurosci 7:711-718. CrossRef Medline

Misonou H, Mohapatra DP, Trimmer JS (2005) Kv2.1: a voltage-gated K+ channel critical to dynamic control of neuronal excitability. Neurotoxicology 26:743-752. CrossRef Medline

Mohapatra DP, Park KS, Trimmer JS (2007) Dynamic regulation of the voltage-gated Kv2.1 potassium channel by multisite phosphorylation. Biochem Soc Trans 35:1064-1068. CrossRef Medline

Mohapatra DP, Misonou H, Pan SJ, Held JE, Surmeier DJ, Trimmer JS (2009) Regulation of intrinsic excitability in hippocampal neurons by activity-dependent modulation of the KV2.1 potassium channel. Channels (Austin) 3:46-56. CrossRef Medline

Murakoshi H, Trimmer JS (1999) Identification of the Kv2.1 $\mathrm{K}^{+}$channel as a major component of the delayed rectifier $\mathrm{K}+$ current in rat hippocampal neurons. J Neurosci 19:1728-1735. Medline

Murakoshi H, Shi G, Scannevin RH, Trimmer JS (1997) Phosphorylation of the Kv2.1 $\mathrm{K}^{+}$channel alters voltage-dependent activation. Mol Pharmacol 52:821-828. CrossRef Medline

Nataraj K, Le Roux N, Nahmani M, Lefort S, Turrigiano G (2010) Visual deprivation suppresses $\mathrm{L} 5$ pyramidal neuron excitability by preventing the induction of intrinsic plasticity. Neuron 68:750-762. CrossRef Medline

Neher E (1992) Correction for liquid junction potentials in patch clamp experiments. Meth Enzymol 207:123-131. CrossRef Medline

O'Connell KM, Loftus R, Tamkun MM (2010) Localization-dependent activity of the Kv2.1 delayed-rectifier K+ channel. Proc Natl Acad Sci U S A 107:12351-12356. CrossRef Medline

Plant LD, Dowdell EJ, Dementieva IS, Marks JD, Goldstein SA (2011) SUMO modification of cell surface Kv2.1 potassium channels regulates the activity of rat hippocampal neurons. J Gen Physiol 137:441-454. CrossRef Medline

Raman IM, Bean BP (2001) Inactivation and recovery of sodium currents in cerebellar Purkinje neurons: evidence for two mechanisms. Biophys J 80:729-737. CrossRef Medline

Scannevin RH, Murakoshi H, Rhodes KJ, Trimmer JS (1996) Identification of a cytoplasmic domain important in the polarized expression and clustering of the Kv2.1 $\mathrm{K}^{+}$channel. J Cell Biol 135:1619-1632. CrossRef Medline

Schoppa NE, Sigworth FJ (1998) Activation of shaker potassium channels. III. an activation gating model for wild-type and V2 mutant channels. J Gen Physiol 111:313-342. CrossRef Medline

Spruston N, Johnston D (1992) Perforated patch-clamp analysis of the passive membrane properties of three classes of hippocampal neurons. J Neurophysiol 67:508-529. Medline

Staff NP, Jung HY, Thiagarajan T, Yao M, Spruston N (2000) Resting and active properties of pyramidal neurons in subiculum and CA1 of rat hippocampus. J Neurophysiol 84:2398-2408. Medline

Steinert JR, Robinson SW, Tong H, Haustein MD, Kopp-Scheinpflug C, Forsythe ID (2011) Nitric oxide is an activity-dependent regulator of target neuron intrinsic excitability. Neuron 71:291-305. CrossRef Medline

Swartz KJ, MacKinnon R (1995) An inhibitor of the Kv2.1 potassium channel isolated from the venom of a chilean tarantula. Neuron 15:941-949. CrossRef Medline

Swartz KJ, MacKinnon R (1997) Hanatoxin modifies the gating of a voltagedependent $\mathrm{K}+$ channel through multiple binding sites. Neuron 18:665673. CrossRef Medline

Tong H, Kopp-Scheinpflug C, Pilati N, Robinson SW, Sinclair JL, Steinert JR, Barnes-Davies M, Allfree R, Grubb BD, Young SM Jr, Forsythe ID (2013) Protection from noice-induced hearing loss by Kv2.2 potassium currents in the central medial olivocochlear system J Neurosci 33:9113-9121. CrossRef

Trimmer JS (1991) Immunological identification and characterization of a delayed rectifier $\mathrm{K}^{+}$channel polypeptide in rat brain. Proc Natl Acad Sci U S A 88:10764-10768. CrossRef Medline

Trimmer JS, Rhodes KJ (2004) Localization of voltage-gated ion channels in mammalian brain. Annu Rev Physiol 66:477-519. CrossRef Medline

Vacher H, Mohapatra DP, Trimmer JS (2008) Localization and targeting of voltage-dependent ion channels in mammalian central neurons. Physiol Rev 88:1407-1447. CrossRef Medline

Whyment AD, Coderre E, Wilson JM, Renaud LP, O’Hare E, Spanswick D (2011) Electrophysiological, pharmacological and molecular profile of the transient outward rectifying conductance in rat sympathetic preganglionic neurons in vitro. Neuroscience 178:68-81. CrossRef Medline 